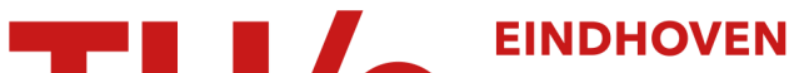 \\ UNIVERSITY OF \\ TECHNOLOGY
}

\section{Flow boiling heat transfer of propane in $1.0 \mathrm{~mm}$ tube}

Citation for published version (APA):

Diehl de Oliveira, J., Passos, J. C., Biancon Copetti, J., \& van der Geld, C. W. M. (2018). Flow boiling heat transfer of propane in $1.0 \mathrm{~mm}$ tube. Experimental Thermal and Fluid Science, 96, 243-256.

https://doi.org/10.1016/j.expthermflusci.2018.03.010

DOI:

10.1016/j.expthermflusci.2018.03.010

Document status and date:

Published: 01/09/2018

Document Version:

Accepted manuscript including changes made at the peer-review stage

Please check the document version of this publication:

- A submitted manuscript is the version of the article upon submission and before peer-review. There can be important differences between the submitted version and the official published version of record. People interested in the research are advised to contact the author for the final version of the publication, or visit the $\mathrm{DOI}$ to the publisher's website.

- The final author version and the galley proof are versions of the publication after peer review.

- The final published version features the final layout of the paper including the volume, issue and page numbers.

Link to publication

\section{General rights}

Copyright and moral rights for the publications made accessible in the public portal are retained by the authors and/or other copyright owners and it is a condition of accessing publications that users recognise and abide by the legal requirements associated with these rights.

- Users may download and print one copy of any publication from the public portal for the purpose of private study or research.

- You may not further distribute the material or use it for any profit-making activity or commercial gain

- You may freely distribute the URL identifying the publication in the public portal.

If the publication is distributed under the terms of Article $25 f a$ of the Dutch Copyright Act, indicated by the "Taverne" license above, please follow below link for the End User Agreement:

www.tue.nl/taverne

Take down policy

If you believe that this document breaches copyright please contact us at:

openaccess@tue.nl

providing details and we will investigate your claim. 


\section{FLOW BOILING HEAT TRANSFER OF PROPANE IN 1.0 mm TUBE}

\section{Highlights}

- Flow patterns are studied during flow boiling of R-290.

- A model to predict flow patterns is proposed.

- The heat transfer coefficient is investigated.

- The influence of flow patterns on the heat transfer coefficient is observed.

- Heat transfer coefficient results are compared to several predicted correlations. 


\title{
FLOW BOILING HEAT TRANSFER OF PROPANE IN 1.0 mm TUBE
}

\author{
Jeferson Diehl de Oliveira*, Júlio Cesar Passos
}

Department of Mechanical Engineering, LEPTEN, Laboratory of Process of Engineering and Energy Technology,

Federal University of Santa Catarina, Florianopólis, 88010-900 SC, Brazil

*jeferson.physics@gmail.com

Jacqueline Biancon Copetti

Mechanical Engineering Graduate Program, LETEF, Laboratory of Thermal and Fluid Dynamic Studies, University of Vale do Rio dos Sinos, São Leopoldo, 93022-750 RS, Brazil

Cees W. M. van der Geld

Department of Chemical Engineering \& Chemistry, Eindhoven University of Technology, Den Dolech 2, 5612 AZ Eindhoven, The Netherlands

*Corresponding author. Tel.:+55 513591 1100; fax: +55 5135908172.

E-mail address: jeferson.physics@gmail.com (J.D. Oliveira) 


\title{
FLOW BOILING HEAT TRANSFER OF PROPANE IN 1.0 mm TUBE
}

\author{
Jeferson Diehl de Oliveira*, Julio Cesar Passos \\ Department of Mechanical Engineering, LEPTEN, Laboratory of Process of Engineering and \\ Energy Technology, Federal University of Santa Catarina, Florianopólis, 88010-900 SC, Brazil \\ *jeferson.physics@gmail.com \\ Jacqueline Biancon Copetti \\ Mechanical Engineering Graduate Program, Laboratory of Thermal and Fluid Dynamic \\ Studies, University of Vale do Rio dos Sinos-Unisinos, São Leopoldo, 93022-750 RS, Brazil \\ Cees W. M. van der Geld \\ Department of Chemical Engineering \& Chemistry, Eindhoven University of Technology, \\ Den Dolech 2, 5612 AZ Eindhoven, The Netherlands
}

\begin{abstract}
Flow patterns and local heat transfer coefficients were investigated experimentally during flow boiling of R-290 in a tube with inner diameter equal to $1.0 \mathrm{~mm}$. The tests were conducted at heat fluxes ranging from 5 to $60 \mathrm{~kW} / \mathrm{m}^{2}$, mass flux from 240 to $480 \mathrm{~kg} /\left(\mathrm{m}^{2} \mathrm{~s}\right)$ at $25{ }^{\circ} \mathrm{C}$ saturation temperature. Both mass flux and heat flux have a significant influence on the heat transfer coefficient. A new flow pattern identification method is proposed, using non-dimensional parameters based on phase velocities and heat flux. The main flow patterns identified were bubbly, plug, slug, churn, wavy- and smooth-annular flow. Convective boiling was found to be predominant for most flow patterns. Moreover, the resulting heat transfer coefficients were compared with predicting correlations available in the literature.
\end{abstract}

Keywords: heat transfer, flow boiling, propane, small tube, flow patterns

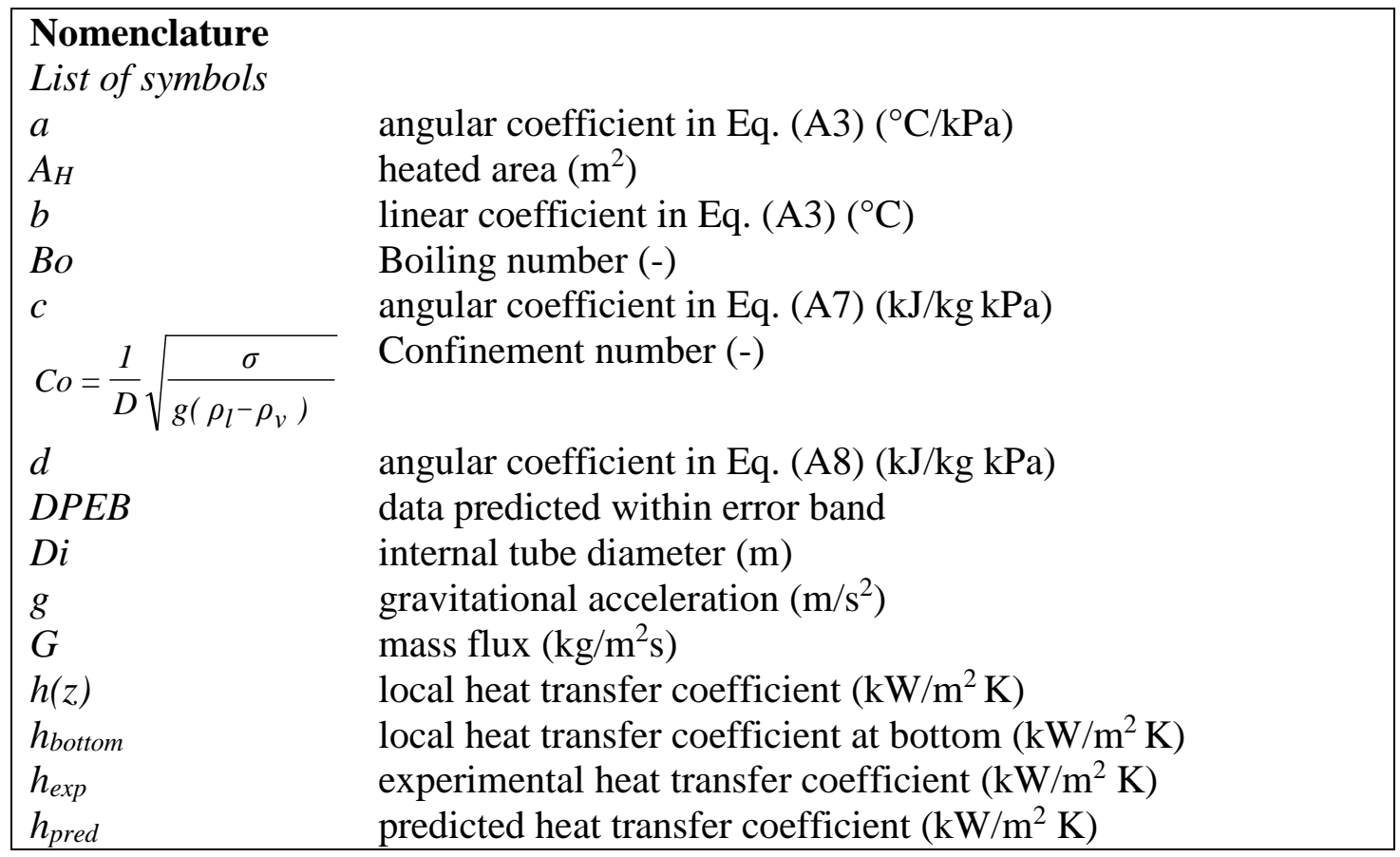




\begin{tabular}{|c|c|}
\hline$h_{\text {top }}$ & local heat transfer coefficient at top $\left(\mathrm{kW} / \mathrm{m}^{2} \mathrm{~K}\right)$ \\
\hline$i(z)$ & local enthalpy (kJ/kg) \\
\hline$I$ & direct electric current (A) \\
\hline$i_{l}$ & liquid enthalpy (kJ/kg) \\
\hline$i_{v}$ & vapor enthalpy $(\mathrm{kJ} / \mathrm{kg})$ \\
\hline$i_{l v}$ & latent heat of vaporization $(\mathrm{kJ} / \mathrm{kg})$ \\
\hline$i_{i-P H}$ & pre-heater inlet enthalpy $(\mathrm{kJ} / \mathrm{kg})$ \\
\hline$i_{i-T S}$ & test section inlet enthalpy $(\mathrm{kJ} / \mathrm{kg})$ \\
\hline$j_{l(o-T S)}$ & superficial liquid velocity in test section outlet $(\mathrm{m} / \mathrm{s})$ \\
\hline$j_{v(o-T S)}$ & superficial vapor velocity in test section outlet $(\mathrm{m} / \mathrm{s})$ \\
\hline$k_{S S}$ & thermal conductivity of stainless steel $(\mathrm{W} / \mathrm{m} \mathrm{K})$ \\
\hline$L$ & total length (mm) \\
\hline$L_{h}$ & heated length of test section (mm) \\
\hline$\dot{m}$ & mass flow rate $(\mathrm{kg} / \mathrm{s})$ \\
\hline$M B E=\frac{1}{n} \sum_{i=1}^{n}\left(h_{\text {pred }_{i}}-h_{\exp _{i}}\right)$ & mean bias error $(\%)$ \\
\hline$n$ & number of measurements \\
\hline$p_{i-T S}$ & pressure (kPa) \\
\hline$p_{\text {sat }}$ & saturation pressure $(\mathrm{kPa})$ \\
\hline$q_{P H}$ & heat rate at pre-heater (W) \\
\hline$q_{T S}$ & heat rate at test section (W) \\
\hline$q^{\prime \prime} T S$ & heat flux at test section $\left(\mathrm{W} / \mathrm{m}^{2}\right)$ \\
\hline$\dot{q}_{T S}$ & volumetric heat generation at test section $\left(\mathrm{W} / \mathrm{m}^{3}\right)$ \\
\hline$R a$ & absolute internal roughness ( $\mu \mathrm{m})$ \\
\hline$r_{e}$ & external radius (m) \\
\hline$r_{i}$ & internal radius (m) \\
\hline$R M S E=\sqrt{\frac{1}{n} \sum_{i=1}^{n}\left[\left(h_{\text {pred }_{i}}-h_{\mathrm{e}}\right.\right.}$ & $\left.\left.h_{\exp _{i}}\right) / h_{\exp _{i}}\right]^{2} \times 100$ \\
\hline$S$ & slip ratio (-) \\
\hline$T_{e w}$ & external wall temperature $\left({ }^{\circ} \mathrm{C}\right)$ \\
\hline$T_{i-T S}$ & refrigerant inlet temperature at test section $\left({ }^{\circ} \mathrm{C}\right)$ \\
\hline$T_{i w}$ & internal wall temperature $\left({ }^{\circ} \mathrm{C}\right)$ \\
\hline$T_{o-T S}$ & refrigerant outlet temperature at test section $\left({ }^{\circ} \mathrm{C}\right)$ \\
\hline$T_{\text {sat }}$ & saturation temperature $\left({ }^{\circ} \mathrm{C}\right)$ \\
\hline$T_{w, b o t t o m}$ & external wall bottom temperature $\left({ }^{\circ} \mathrm{C}\right)$ \\
\hline$T_{w, t o p}$ & external wall top temperature $\left({ }^{\circ} \mathrm{C}\right)$ \\
\hline$U$ & direct voltage $(\mathrm{V})$ \\
\hline$u_{l(o-T S)}$ & Liquid mean velocity in two-phase flow (m/s) \\
\hline$u_{v(o-T S)}$ & Vapor mean velocity in two-phase flow (m/s) \\
\hline$x$ & vapor quality (-) \\
\hline$X_{(i-T S)}$ & vapor quality in the test section inlet (-) \\
\hline$X_{(0-T S)}$ & vapor quality in the test section outlet (-) \\
\hline z & location in test section (mm) \\
\hline \multicolumn{2}{|l|}{ Greek symbols } \\
\hline$\alpha$ & void fraction (-) \\
\hline$\beta$ & Parameter to determine the flow pattern (-) \\
\hline$\rho_{l}$ & liquid density $\left(\mathrm{kg} / \mathrm{m}^{3}\right)$ \\
\hline$\rho_{v}$ & vapor density $\left(\mathrm{kg} / \mathrm{m}^{3}\right)$ \\
\hline$\sigma$ & surface tension (N/m) \\
\hline
\end{tabular}




\section{INTRODUCTION}

Nowadays, hydrocarbons are seen as an interesting choice as replacements for fluid refrigerants such as CFCs, HCFCs and HFCs. Among several applications of hydrocarbons, we highlight the use as refrigerant in compact heat exchangers, air conditioners and electronic cooling.

Quite some experimental work has been performed on the heat transfer, pressure loss and flow patterns in boiling and condensation of hydrocarbons in small geometries to facilitate the design of e.g. compact heat exchangers. The following intends to offer a comprehensive summary.

Brutin and Tadrist (2004) investigated the flow boiling heat transfer of R-601 (n-pentane) in a single vertical rectangular minichannel with hydraulic diameter of $0.889 \mathrm{~mm}$ at constant saturation temperature of $25^{\circ} \mathrm{C}$ and heat flux ranging from 15.7 to $125.6 \mathrm{~kW} / \mathrm{m}^{2}$. The experimental results show that heat transfer coefficient increases with the increase of mass flux and also has a dependence of heat flux. Lee et al. (2005) measured the heat transfer during flow boiling of R-290 (propane), R-600a (isobutane), R-1270 (propylene) and HCFC R-22 in a horizontal double pipe heat exchanger as test section with internal diameters of 9.52 and 12.7 $\mathrm{mm}$. The tests were performed for mass fluxes ranging from 50 to $200 \mathrm{~kg} /\left(\mathrm{m}^{2} \mathrm{~s}\right)$ and saturation temperatures between $-10^{\circ} \mathrm{C}$ and $10^{\circ} \mathrm{C}$. As a result, it was found that the heat transfer coefficients of the hydrocarbons are higher than that of R-22 for two diameters studied. Wen et al. (2007) studied the flow boiling heat transfer characteristics for the R-290/R-600a mixture with lubricating oil in serpentine U-tubes with $2.46 \mathrm{~mm}$ ID (inner diameter). The tests were performed for heat flux ranging from 15 to $25 \mathrm{~kW} / \mathrm{m}^{2}$ and mass flux from 100 to $320 \mathrm{~kg} /\left(\mathrm{m}^{2} \mathrm{~s}\right)$. They concluded that the heat transfer coefficients of R-600a and R-290 increased with increasing vapor quality for $x>0.4$, but with oil, the heat transfer coefficient decreased considerably.

Characteristics of flow boiling heat transfer of R-290 were investigated by Choi et al. (2009) in horizontal smooth tubes with 1.5 and $3 \mathrm{~mm}$ ID for mass fluxes ranging from 50 to 400 $\mathrm{kg} /\left(\mathrm{m}^{2} \mathrm{~s}\right)$ and heat fluxes from 5 to $20 \mathrm{~kW} / \mathrm{m}^{2}$ at saturation temperatures of 0,5 and $10{ }^{\circ} \mathrm{C}$. They observed that the heat transfer coefficient increases with a decrease of inner diameter and with an increase of saturation temperature. Copetti et al. (2013) studied the flow boiling heat transfer characteristics of R-600a in a horizontal minichannel with inner diameter of $2.6 \mathrm{~mm}$ with saturation temperature of $22^{\circ} \mathrm{C}$, mass flux ranging from 240 and $440 \mathrm{~kg} /\left(\mathrm{m}^{2} \mathrm{~s}\right)$ and heat flux between 44 and $95 \mathrm{~kW} / \mathrm{m}^{2}$. Test results showed a significant influence of heat flux on heat transfer coefficient in low vapor quality conditions. Such an influence vanished in cases of high vapor quality conditions and high mass fluxes. Del Col et al. (2014) performed studies on heat transfer of R-290 during flow boiling with a horizontal tube with $0.96 \mathrm{~mm}$ ID at saturation temperature of $31{ }^{\circ} \mathrm{C}$ with mass flux ranging from 100 to $1000 \mathrm{~kg} /\left(\mathrm{m}^{2} \mathrm{~s}\right)$ and heat flux between 10 and $315 \mathrm{~kW} / \mathrm{m}^{2}$. As a result, the heat transfer coefficient has considerable dependence of heat flux and vapor quality. Wang et al. (2014) studied the flow boiling heat transfer of R-290 in horizontal channels with $6 \mathrm{~mm}$ inner diameter for heat flux ranging from 11.7 to $87.1 \mathrm{~kW} / \mathrm{m}^{2}$, mass flux ranging between 62 and $104 \mathrm{~kg} /\left(\mathrm{m}^{2} \mathrm{~s}\right)$ at saturation temperatures from -35 to $-1.9{ }^{\circ} \mathrm{C}$. Their results indicate that the heat transfer coefficient increases with the increase of heat flux, mass flux and saturation temperature. The variation of saturation temperature changes thermophysical properties such as viscosity and density of both phases, consequently, causing influence on convective parameters.

Oliveira et al. (2016) investigated the influence of flow patterns on the heat transfer coefficient in flow boiling of R-600a in a horizontal tube with $1 \mathrm{~mm}$ ID for heat fluxes ranging 
from 5 to $60 \mathrm{~kW} / \mathrm{m}^{2}$ and mass fluxes between 240 and $480 \mathrm{~kg} /\left(\mathrm{m}^{2} \mathrm{~s}\right)$ at saturation temperature of $25{ }^{\circ} \mathrm{C}$. According to the authors, the two-phase flow patterns observation has shown a dominance of intermittent churn, wavy-annular and smooth-annular flow regimes. Plug and slug flow were observed only during lower vapor quality conditions, indicating that such patterns are related to nucleate boiling dominance. A study of flow patterns during flow boiling and condensation also using helically dimpled and smooth tubes was developed by Mashouf et al. (2017) using practically the same parameters implemented by Shafaee et al. (2016a) for evaporation case. For condensation, the tests were performed at saturation temperatures varying from $38{ }^{\circ} \mathrm{C}$ to $42{ }^{\circ} \mathrm{C}$ with mass flux between 114 and $368 \mathrm{~kg} /\left(\mathrm{m}^{2} \mathrm{~s}\right)$. For both evaporation and condensation tests, stratified-wavy, intermittent and annular flows were observed in the smooth tube, but stratified-wavy was not seen in the dimpled tube.

Table 1 presents a summary of the recent literature concerning flow boiling for single and multi-channel configurations with hydrocarbons, including saturation condition, hydraulic diameters, flow patterns and other relevant information.

As an addition to the above listed studies, the present investigation concerns flow patterns assessments during flow boiling of R-290 in a micro channel, $1 \mathrm{~mm} \mathrm{ID,} \mathrm{as} \mathrm{well} \mathrm{as} \mathrm{the}$ corresponding heat transfer characteristics as well as the effects of gravity, heat flux and mass flux on heat flux at a saturation temperature of $25^{\circ} \mathrm{C}$. 


\begin{tabular}{|c|c|c|c|c|c|c|c|c|}
\hline Author & Geometry & $\begin{array}{l}\text { Orientation/ } \\
\text { D [mm] }\end{array}$ & Fluids & $\mathbf{T}_{\text {sat }}\left[{ }^{\circ} \mathbf{C}\right]$ & $G\left[\mathrm{kgm}^{-2} \mathrm{~s}^{-1}\right]$ & $q^{\prime \prime}\left[\mathrm{kWm}^{-2}\right]$ & $x[-]$ & Remarks \\
\hline Aprin et al. (2011) & NS & V/NS & R-600a, R-290 and R-601 & $*$ & $8-45$ & $3-53$ & NS & $\begin{array}{c}\text { * Saturation temperature was } \\
\text { obtained as a function of average } \\
\text { pressure ( } 0.2-12 \text { bar) } \\
\text { The heat transfer coefficient was } \\
\text { measured in a tube bundle. }\end{array}$ \\
\hline $\begin{array}{c}\text { Maqbool et al. } \\
(2013)\end{array}$ & C & V/1.7 & R-290 & 23,33 and 43 & $100-500$ & $5-280$ & $0.0-1$ & - \\
\hline Chen and Shi (2013) & C & $\mathrm{H} / \mathbf{8 . 0}$ & LNG & $*$ & $49.2-201.8$ & $8-36$ & NS & $\begin{array}{c}\text { *Saturation condition was } \\
\text { established as a function of inlet } \\
\text { pressure ranging from } 65.7 \text { to } \\
82.2 \mathrm{kPa} \\
\end{array}$ \\
\hline Wen et al. (2014) & C & $\mathrm{H} / 7.5$ & R-600a & 10 & $120-1100$ & $12-65$ & $0.076-0.87$ & $\begin{array}{c}\text { Both heat transfer and pressure } \\
\text { drop were studied in a } \\
\text { circular pipe within dispersed- } \\
\text { copper porous inserts } \\
\end{array}$ \\
\hline Anwar et al. (2015) & $\mathrm{C}$ & V/1.6 & R-600a & 27 and 32 & $50-350$ & $20-130$ & $0.0-0.97$ & Dry-out effect was observed \\
\hline Chen at al. (2015) & $\mathbf{C}$ & $\mathrm{H} / 5.4$ & R-600a+mineral naphthalin oil & NS & $11.9-15.99$ & $2.5-3.3$ & Up to 0.95 & - \\
\hline $\begin{array}{c}\text { Melnyk and } \\
\text { Zhelezny (2015) } \\
\end{array}$ & C & $\mathrm{H} / 5.4$ & R-600a+mineral naphthalin oil & NS & $14.75-18.36$ & $\approx 3.8$ & Up to 0.97 & - \\
\hline Qiu et al. (2015) & C & $\mathrm{H} / \mathbf{8}$ & $\begin{array}{c}\text { R-600a, R-1234ze(E) and } \\
\text { R1234ze(E)/R32 (27/73 mass \%) }\end{array}$ & 20 & $200-400$ & $5-10$ & $0.05-0.85$ & $\begin{array}{c}\text { Both heat transfer and pressure } \\
\text { drop were studied }\end{array}$ \\
\hline $\begin{array}{c}\text { Apaydin and } \\
\text { Heperkan (2016) } \\
\end{array}$ & C & $\mathrm{V} / \mathbf{0 . 8}$ & R-600a & - & $8.99-9.97$ & $\begin{array}{l}\text { Adiabatic } \\
\text { condition }\end{array}$ & NS & - \\
\hline $\begin{array}{c}\text { Kanizawa et al. } \\
\text { (2016) }\end{array}$ & C & H/0.38 - 2.6 & R-134a, R-245fa and R-600a & $21.5-58.3$ & $49-2200$ & $5-185$ & $0.01-0.93$ & - \\
\hline $\begin{array}{l}\text { Shafaee et al. } \\
\quad(2016 b)\end{array}$ & C & $\begin{array}{c}\mathrm{H} / *^{*} 0.5,1.0 \text { and } \\
1.5\end{array}$ & R-600a & $* *$ & $109.2-505$ & $6-40$ & $0.08-0.7$ & $\begin{array}{c}* \text { Coiled wire insert tubes. } \\
* * \text { Saturation temperature was } \\
\text { obtained as a function of average } \\
\text { pressure }(4-6 \text { bar) }\end{array}$ \\
\hline Chávez et al (2017) & $\mathbf{R}$ & $\mathbf{H} / *$ & R-600a, R-290 and R-1270 & 25 & $165-823$ & Up to 400 & NS & $\begin{array}{l}\text { *The test section is composed of } \\
\text { fifty channels of cross sectional } \\
\text { areas of } 0.123 \times 0.494 \mathrm{~mm}^{2} \text {. } \\
\text { ONB was analyzed as function of } \\
\text { mass flux, subcooling conditions } \\
\text { and heat flux. }\end{array}$ \\
\hline Del Col et al. (2017) & C & H/0.96 & R-1270 & 30 & $100-600$ & $11-244$ & $0.02-0.62$ & $\begin{array}{l}\text { Condensation heat transfer of } \\
\text { R-290 and R-1270 was also } \\
\text { studied. }\end{array}$ \\
\hline Oliveira et al. (2017) & $\mathrm{C}$ & $\mathrm{H} / \mathbf{1 . 0}$ & R-600a and R-290 & 25 & $240-480$ & $5-60$ & $0.0-0.99$ & - \\
\hline $\begin{array}{l}\text { Sempértegui-Tapia } \\
\text { et al. (2017) }\end{array}$ & C & $\mathrm{H} / \mathbf{1 . 1}$ & $\begin{array}{c}\text { R-134a, R-1234yf, R-1234ze(E) } \\
\text { and R-600a }\end{array}$ & 31 and 41 & $200-800$ & $15-145$ & $0.05-0.95$ & - \\
\hline Yang et al. (2017) & $\mathbf{C}$ & $\mathrm{H} / \mathbf{6}$ & R-600a & $9.2,21.3$ and 30.8 & $67-194$ & $10.6-75$ & $0-1.0$ & - \\
\hline
\end{tabular}

$\mathrm{C}=$ circular; $\mathrm{F}$ = flattened; $\mathrm{H}=$ horizontal; $\mathrm{NS}$ = Not specified; $\mathrm{R}=$ rectangular; $\mathrm{V}$ = vertical; 



\section{EXPERIMENTAL APPARATUS AND METHODOLOGY}

\subsection{Test facility and instrumentation}

An experimental facility was developed to investigate the flow boiling and pressure drop in a horizontal small channel. Fig. 1 shows the details of such set up.

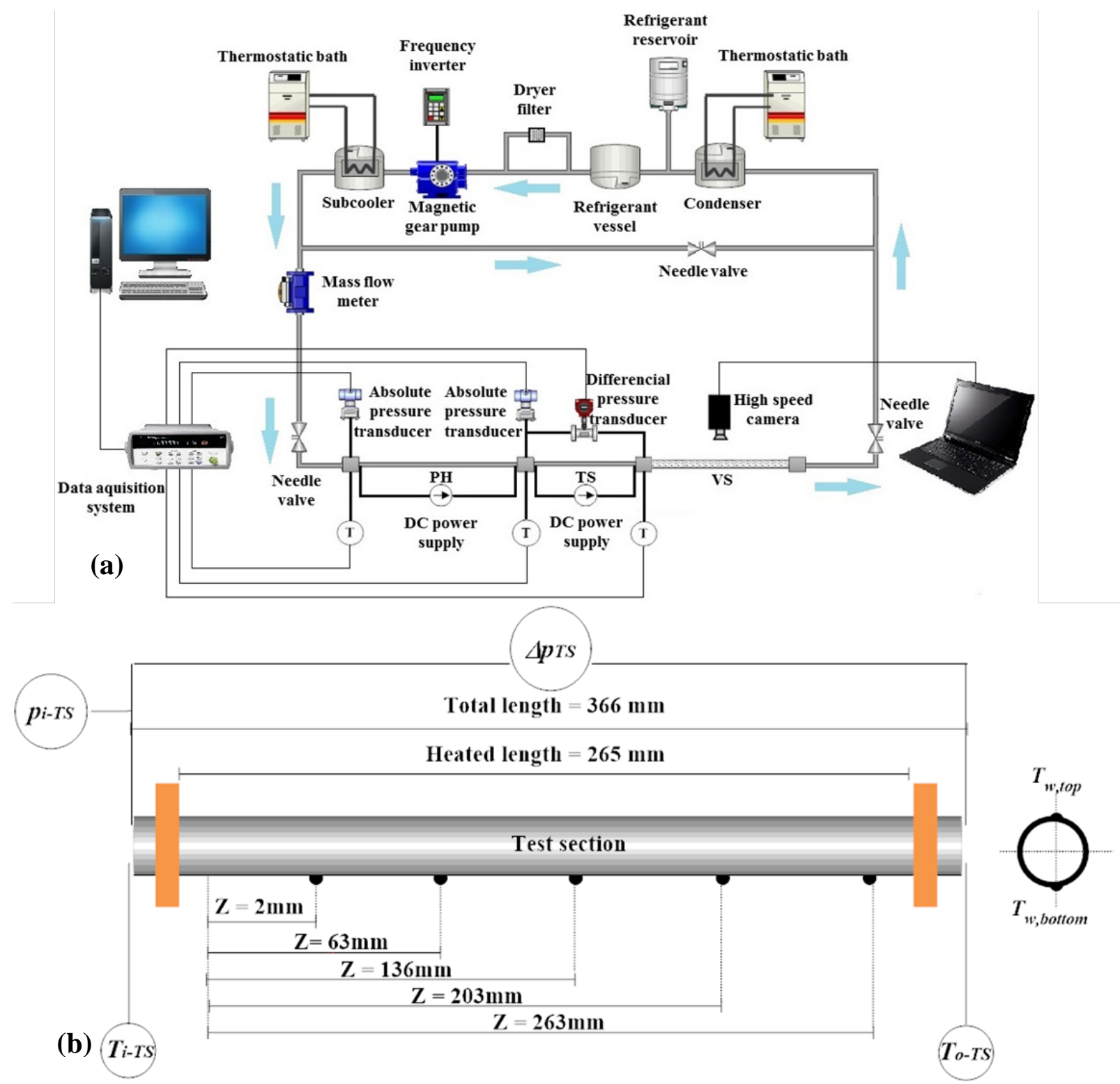

Figure 1. (a) Experimental test rig; (b) Schematic of test section and thermocouples in different positions along the tube.

The experimental system consists of a loop that provides controlled mass flux, and it was designed to test different fluids under a wide range of flow conditions. The main part of the loop has a pre-heater, a test section and a visualization section. The secondary part consists of a condenser, and a subcooler, and they both have independent circuits of ethylene-glycol/water solution as the secondary refrigerant, and the temperature is controlled by a thermostatic bath (Fig. 1a). This set up controls the refrigerant saturation pressure and temperature. A liquid refrigerant vessel maintains a constant static pressure at the pump suction, assuring that the pump works uniformly and under immersion, avoiding cavitation. The subcooler is used to compensate the refrigerant temperature rises, after it passes by the gear pump, and also to assure that only 
subcooled liquid enters the flow meter. The pre-heater establishes the experimental conditions entering the test section immediately downstream. It consists of a horizontal stainless-steel tube with $1.0 \mathrm{~mm}$ internal diameter with a total length of $515 \mathrm{~mm}$ and heated length of $440 \mathrm{~mm}$. This tube is uniformly heated by direct application of an electrical current in the wall (Joule effect), the intensity of which is controlled by the power supply SORENSEN model DCS 8-125E which provides both direct voltage and electric current measurements.

The test section consists of the same tube and diameter with total length of $366 \mathrm{~mm}$, heated length of $265 \mathrm{~mm}$. As well as the pre-heater, the test section is heated by Joule effect, the power intensity of which is controlled by the power supply. The absolute internal roughness $(R a)$ of the tube was measured with a STARRETT ${ }^{\mathrm{TM}}$ roughness tester, model SR 200, and was found to be $1.48 \mu \mathrm{m}$. There is a visualization section downstream of the test section with a $136 \mathrm{~mm}$ length glass tube with the same test section internal diameter. Both pre-heater and test section are thermally insulated.

The refrigerant enters the pre-heater as a subcooled liquid and achieves the saturation condition upstream of its outlet. This condition defines the vapor quality in the test section inlet, and varies according to the heat flux imposed in the pre-heater. Two absolute pressure transducers and two $0.076 \mathrm{~mm}$ type-E thermocouples, in direct contact with the refrigerant, carry out the pressure and temperature measurements, at the inlet and outlet of the pre-heater. In the test section, refrigerant temperatures are measured at the inlet and outlet of the tube, and the tube wall temperatures are measured by thermocouples directly fixed by a thermally conductive paste at five axial positions along the tube, with two thermocouples at each position, separated by $180^{\circ}$ one from the other (Fig. 1b). The differential pressure transducer allows the determination of the outlet pressure. A frequency inverter is responsible for the fine adjustment during the control of the pump flow rate and a by-pass line downstream of the pump, controlled by a needle valve, is used for coarse adjustment of flow rates. Two other needle valves (downstream the preheater and upstream of the visualization section) are used to reduce instabilities pressure during testing in different flow boiling conditions.

The pressure transducers, thermocouples, mass flow and power meter were connected to an acquisition data system composed of a multimeter (Agilent, model 34970A), controlled by a computer via an RS232 interface. The flow patterns observed in the visualization section during tests were recorded with a high-speed camera MotionPro model Y4-S1, using 3000 frames per second. Preliminary tests in single-phase with heating were realized to estimate the heat loss in both preheater and test section. In both sections, the heat loss was negligible (less than $0.1 \%$ ).

\subsection{Test procedures and data reduction}

Preliminary tests in single-phase with heating were realized to estimate the heat loss in both preheater and test section. In both sections, the heat loss was negligible (less than $0.1 \%$ ).

The experimental conditions for boiling tests are summarized in Tab. 2.

\begin{tabular}{|c|c|c|}
\hline Parameter & Values & Unit \\
\hline Heat flux in test section, $q$ ” TS & $5,10,20,40,60$ & $\mathrm{~kW} / \mathrm{m}^{2}$ \\
\hline Heating power in pre-heater, $q_{P H}$ & $5,15,25,35$ & W \\
\hline Mass flux, $G$ & $240,320,400,480$ & $\mathrm{~kg} /\left(\mathrm{m}^{2} \mathrm{~s}\right)$ \\
\hline Saturation temperature, $T_{\text {sat }}$ & 25 & ${ }^{\circ} \mathrm{C}$ \\
\hline Saturation pressure, $p_{\text {sat }}$ & 952.2 & $\mathrm{kPa}$ \\
\hline
\end{tabular}

For each mass flux condition, the tests were performed by setting the power in $\mathrm{PH}$ and varying the heating condition in the TS, thus resulting in 80 tests, according the conditions shown in Tab. 2. In this way, each condition of the PH establishes the initial vapor quality in the TS that evolves as the heat flux in this section increases. For each test, after reaching the steady- 
state condition, the signals from all sensors were recorded every $5 \mathrm{~s}$ and 100 measurements were carried out.

The experimental data obtained, including vapor quality, internal wall temperature, saturation temperature and heat transfer coefficient, were calculated from measured values for the refrigerant temperatures, wall temperatures in the test section, pressures, flow rate, heat flux and geometrical parameters. All thermodynamics and transport properties used in data reduction and heat transfer correlations were obtained from REFPROP v. 9.1 (Lemmon et al., 2013).

To calculate the heat transfer coefficient, the following assumptions were made:

- Heat transfer in the axial direction can be neglected;

- Volumetric heat generation, and hence heat flux, is uniform along the tube in the test section;

- Pressure drop from the saturation point to the test section outlet is a linear function of tube length. This assumption has been validated with the aid of existing correlations from the literature, based on models with two-phase multipliers.

The heat flux applied to the test section results from Joule's heat generated in the tube wall,

$$
q_{T S}^{\prime \prime}=U I / A_{H}
$$

where $D_{i}$ is the internal diameter, $L_{h}$ is the heated length and $U$ and $I$ represent the voltage and current applied to the test section, respectively, and $A_{H}=\pi D i L h$.

External wall temperatures, $T_{e w}(z)$, were measured at the top and bottom (Fig.1b) of tube perimeter, in the 5 positions (z) along the tube. The local temperature at the inner wall, $T_{i w}(z)$, is calculated assuming pure radial conduction through the wall of the tube, subject to internal heat generation, according to

$$
T_{i w}(z)=T_{e w}(z)+\frac{\dot{q}_{T S}}{4 k_{s S}}\left(r_{e}{ }^{2}-r_{i}^{2}\right)-\frac{\dot{q}_{T S}}{2 k_{s S}} r_{e}{ }^{2} \ln \left(\frac{r_{e}}{r_{i}}\right)
$$

where $\dot{q}_{T S}$ represents the volumetric heat generated along the tube in test section, $k_{s S}$ is the thermal conductivity of stainless steel, and $r_{e}$ e $r_{i}$ are the external and internal radius of test section, respectively.

The local heat transfer coefficients were calculated by Eq.(3) at the top and bottom at any location $z$.

$$
h(z)=\frac{q^{\prime \prime} T S}{T_{i w}(z)-T_{s a t}(z)}
$$

Then, the heat transfer coefficients at locations $z$ along the tube are the average of two local coefficients considering the number of measurements, $n=100$, in each test.

$$
\bar{h}(z)=\sum_{1}^{n}\left(h_{\text {top }}(z)+h_{\text {botom }}(z)\right) /(200)
$$

The local saturation temperature, $T_{\text {sat }}(z)$, was calculated as a function of inlet pressure, $p_{\text {sat, } i \text {, }}$ and pressure drop in test section, $\Delta p_{T S}$, considering the pressure drop as a linear variation along the test section.

$$
p_{\text {sat }(z)}=p_{\text {sat }, i}-\frac{z \Delta p_{T S}}{L}
$$


The vapor quality in the test section inlet was calculated from energy balance in pre-heater, according to:

$$
X_{(i-T S)}=\frac{\left(\frac{q_{P H}}{\dot{m}}+i_{i-P H}\right)-i_{l}\left(p_{s a t}\right)}{i_{l v}\left(p_{s a t}\right)}
$$

where $i_{l}$ and $i_{l v}$ represent the liquid enthalpy and latent heat of vaporization as function of saturation pressure.

The local vapor quality along the test section was calculated as a function of local enthalpy and the enthalpy of test section inlet, by:

$$
x(z)=\frac{i(z)-i_{l}\left(p_{s a t}\right)}{i_{l v}\left(p_{\text {sat }}\right)}
$$

in such case, local enthalpy, $i(z)$, is

$$
i(z)=\left(\frac{q_{T S}(z)}{\dot{m}}+i_{i-T S}\right)
$$

The combined standard uncertainty was used to establish the uncertainty of each parameter measured and calculated. The methodology used for combined uncertainty of main parameters is presented in the Appendix section. However, the results of uncertainty analysis are show in Tab. 3.

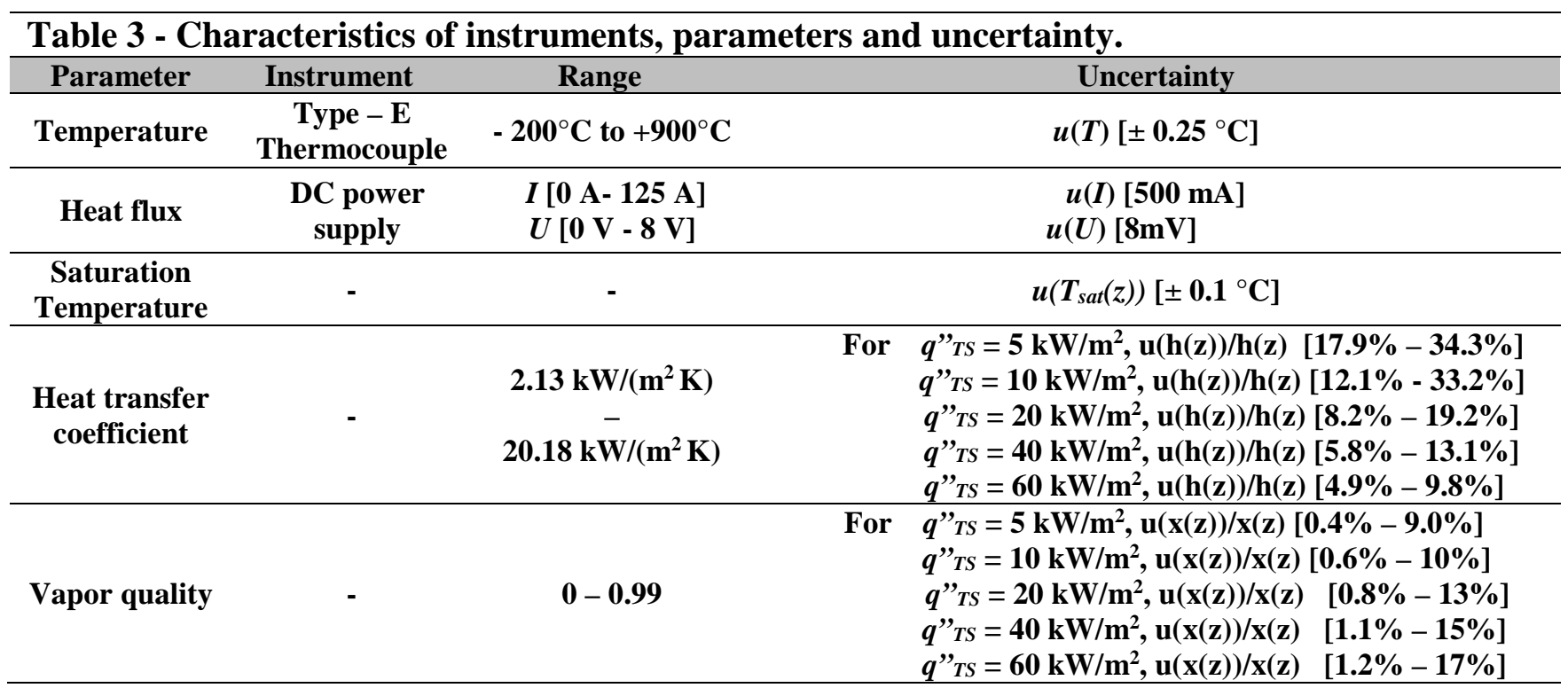

Preliminary single-phase tests were performed in order to determine the thermal losses from the tube surface in $P H$ and $T S$, and the validation of the experimental facility by comparing experimental heat transfer coefficients results with coefficients predicted by correlations. In this case, Dittus-Boelter (1930) and Gnielinski (1976) correlations were chosen, as they are applied to cases involving fully developed flow and constant heat flux in the wall. Fig. 2 presents the results of the experimental heat transfer coefficient and those predicted by the respective correlations as a function of Reynolds number varying between 2000 and 6000 . In summary, the experimental results show agreement with the values obtained by the correlations. Although the Dittus-Boelter correlation was not developed for $R e<10000$, it presents the best fit, with a mean 
bias error of approximately $2.2 \%$, probably due to the effect of reduced diameter. On the other hand, Gnielinski correlation has a mean bias error of $16.5 \%$.

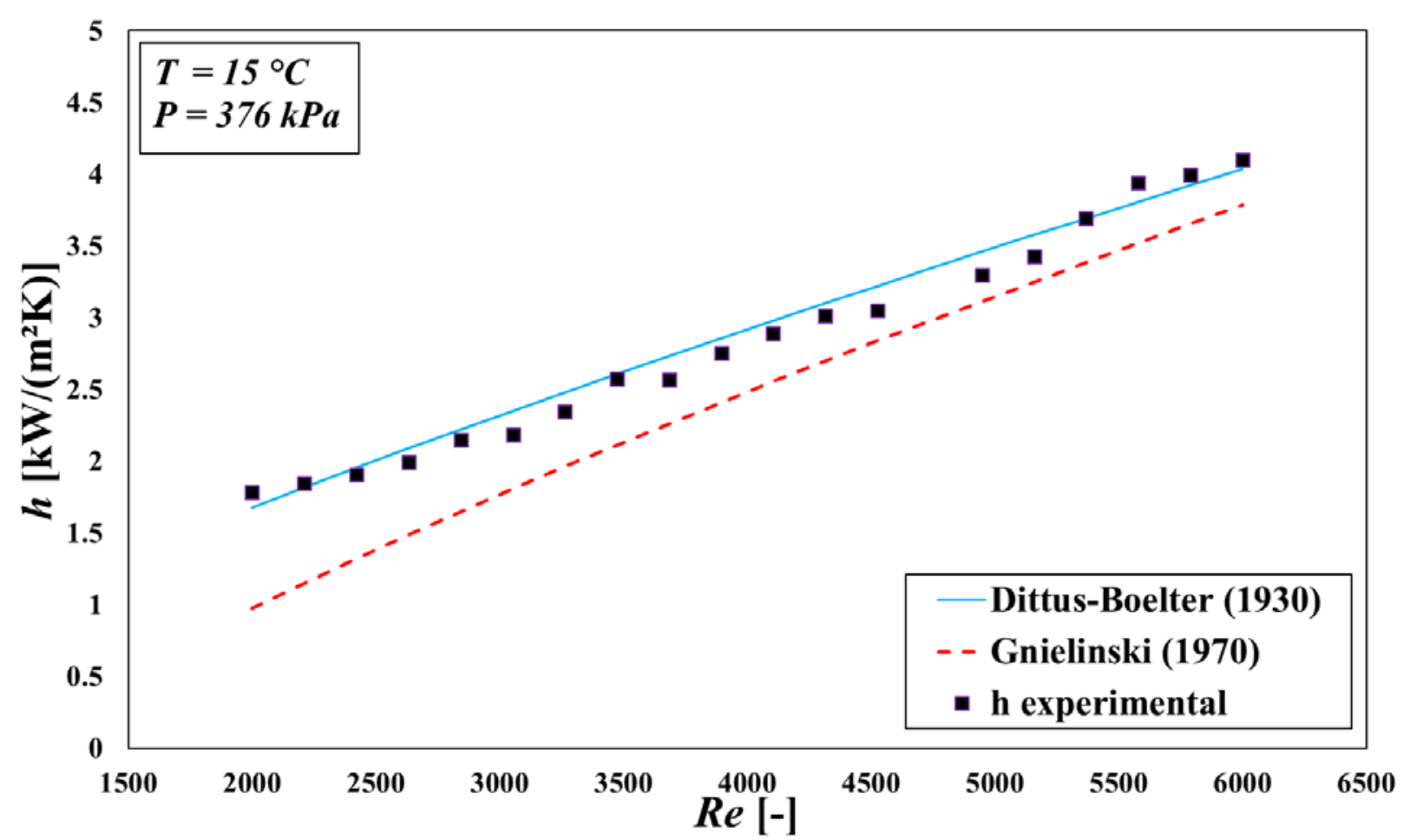

Figure 2. Comparative between experimental and predicted heat transfer coefficients given by Dittus-Boelter (1930) and Gnielinski (1970).

\section{RESULTS}

\subsection{Flow pattern}

The flow patterns were identified by images collected with high-speed camera. For each test, six hundred images (at 3,000 fps) were obtained to ensure a consistent pattern analysis, thus obtaining more than 234,000 images as result of all tests. The predominant patterns observed were plug, slug, churn and wavy-annular flows.

Figure 3 presents some patterns observed in specific conditions. In all images, parameters (related to test section outlet $o$-TS) as vapor quality $x_{(0-T S)}$, void fraction $\alpha_{(o-T S)}$, slip ratio $S$ and boiling number $B o$ are presented. The void fraction was evaluated with the relation developed by Rouhani and Axelsson (1970), given by Eq. (9), due to the subcooled flow boiling condition in the pre-heater and because of its predictive capacity for lower vapor quality is better when compared to other models.

$$
\alpha_{(o-T S)}=\frac{x_{(o-T S)}}{\rho_{v}}\left\{\left[1+0.12\left(1-x_{(o-T S)}\right)\left(\frac{x_{(o-T S)}}{\rho_{v}}+\frac{1-x_{(o-T S)}}{\rho_{l}}\right)+\frac{1.18\left(1-x_{(o-T S)}\right)\left[g \sigma\left(\rho_{l}-\rho_{v}\right)\right]^{0.25}}{G \rho_{l}^{0.5}}\right\}^{-1}\right.
$$

Although the Rouhani and Axelsson model was developed for vertical flow, it takes important parameters into account that are related to two-phase flow in mini- and microchannels, based on liquid mass density $\rho_{l}$, vapor mass density $\rho_{v}$, gravitational acceleration g and surface tension coefficient $\sigma$. In addition, flow boiling in horizontal mini and micro channels have practically the same radial symmetry in interfacial topology that is found in vertical flow due to 
the dominance of capillarity. Moreover, this model has successfully been applied to horizontal flow boiling for hydrocarbons by Del Col et al. (2014) and Del Col et al. (2017). The visualization study done by Oliveira et al. (2016) and Oliveira et al. (2017) proves the hypothesis of radial symmetry.

Since the slip ratio $S$ and boiling number $B o$ are defined by Eqs. (10) and (11).

$$
\begin{aligned}
& S=\frac{u_{v(o-T S)}}{u_{l(o-T S)}} \equiv \frac{\rho_{l}\left(1-\alpha_{(o-T S)}\right) x_{(o-T S)}}{\rho_{v} \alpha_{(o-T S)}\left(1-x_{(o-T S)}\right)} \\
& B o=\frac{q_{T S}^{\prime \prime}}{G i_{l v}}
\end{aligned}
$$

Patterns as bubbly/plug, plug (vapor plugs are caused by the gathering of small bubbles which subsequently coalesce and become larger and longer) and slug were observed only in cases involving low heat flux and low vapor quality. In fact, bubbles were observed only for $G=$ $480 \mathrm{~kg} /\left(\mathrm{m}^{2} \mathrm{~s}\right)$ and for minimum heat fluxes in both pre-heater and test section. Tests showed that it was not possible to observe bubbly flow for $x_{(0-T S)}>0.05$.

Slug flow is characterized as an "oblong nose" downstream of a liquid slug that protrudes into the core, fills up most of the cross-section area and is caused by the coalescence of plugs along the flow. Such flow pattern, as defined in Fig. 3, was the second pattern observed for low heat fluxes, but for all mass fluxes. For the tests involving slug flow it was found that $0.6<$ $\alpha_{(o-T S)}<0.7$ and $S<1.8$.

The churn pattern can be considered as the transition between slug and annular patterns and it was observed for all mass fluxes and heat fluxes. For $G=320 \mathrm{~kg} /\left(\mathrm{m}^{2} \mathrm{~s}\right)$, churn has a maximum value of $S=2.35$ for $q$ ” TS $=40 \mathrm{~kW} / \mathrm{m}^{2}, x_{(o-T S)}=0.37$ and $\alpha_{(o-T S)}=0.86$. The minimum $S$ is equal to 1.1 for $G=480 \mathrm{~kg} /\left(\mathrm{m}^{2} \mathrm{~s}\right)$ and it was obtained for $q$ ” $T S=5 \mathrm{~kW} / \mathrm{m}^{2}$ with $x_{(o-T S)}=0.16$ and $\alpha_{(o-T S)}$

\begin{tabular}{|c|c|c|c|c|c|}
\hline \multicolumn{6}{|c|}{ Bubbly/plug } \\
\hline$q^{\prime \prime}\left[\mathrm{kW} / \mathrm{m}^{2}\right]$ & $G\left[\mathrm{~kg} /\left(\mathrm{m}^{2} \mathrm{~s}\right)\right]$ & $X_{0-T S}[-]$ & $\alpha_{o-T S}[-]$ & $S[-]$ & \multirow{3}{*}{$\begin{array}{c}\text { Bo }^{2} 10^{5}[-] \\
2.993\end{array}$} \\
\hline & 480 & 0.03 & 0.39 & 1.34 & \\
\hline Flow direction & -4 & U & $\hat{U}$ & & \\
\hline \multicolumn{6}{|c|}{ Plug } \\
\hline$q^{\prime \prime}\left[\mathrm{kW} / \mathrm{m}^{2}\right]$ & $G\left[\mathrm{~kg} /\left(\mathrm{m}^{2} \mathrm{~s}\right)\right]$ & $x_{o-T S}[-]$ & $\alpha_{o-T S}[-]$ & $S[-]$ & \multirow{2}{*}{$\begin{array}{c}\text { Bo } \cdot 10^{5}[-] \\
\quad 6.005\end{array}$} \\
\hline 5 & 240 & 0.05 & 0.511 & 1.38 & \\
\hline \multicolumn{6}{|c|}{ Slug } \\
\hline$q^{\prime \prime}\left[\mathrm{kW} / \mathrm{m}^{2}\right]$ & $G\left[\mathrm{~kg} /\left(\mathrm{m}^{2} \mathrm{~s}\right)\right]$ & $X_{o-T S}[-]$ & $\alpha_{o-T S}[-]$ & $S[-]$ & \multirow{2}{*}{$\begin{array}{c}\text { Bo } \cdot 10^{5}[-] \\
\quad 7.203\end{array}$} \\
\hline 10 & 400 & 0.11 & 0.65 & 1.5 & \\
\hline \multicolumn{6}{|c|}{ Churn } \\
\hline$q^{\prime \prime}\left[\mathrm{kW} / \mathrm{m}^{2}\right]$ & $G\left[\mathrm{~kg} /\left(\mathrm{m}^{2} \mathrm{~s}\right)\right]$ & $X_{o-T S}[-]$ & $\alpha_{o-T S}[-]$ & $S[-]$ & \multirow{2}{*}{$\begin{array}{c}\text { Bo } \cdot 10^{4}[-] \\
\quad 3.694\end{array}$} \\
\hline 40 & 320 & 0.37 & 0.86 & 2.35 & \\
\hline \multicolumn{6}{|c|}{ Wavy annular } \\
\hline$q^{\prime \prime}\left[\mathrm{kW} / \mathrm{m}^{2}\right]$ & $G\left[\mathrm{~kg} /\left(\mathrm{m}^{2} \mathrm{~s}\right)\right]$ & $X_{0-T S}[-]$ & $\alpha_{o-T S}[-]$ & $S[-]$ & Bo $\cdot 10^{4}[-]$ \\
\hline 60 & 400 & 0.44 & 0.88 & 2.5 & 4.55 \\
\hline
\end{tabular}
$=0.74$. 


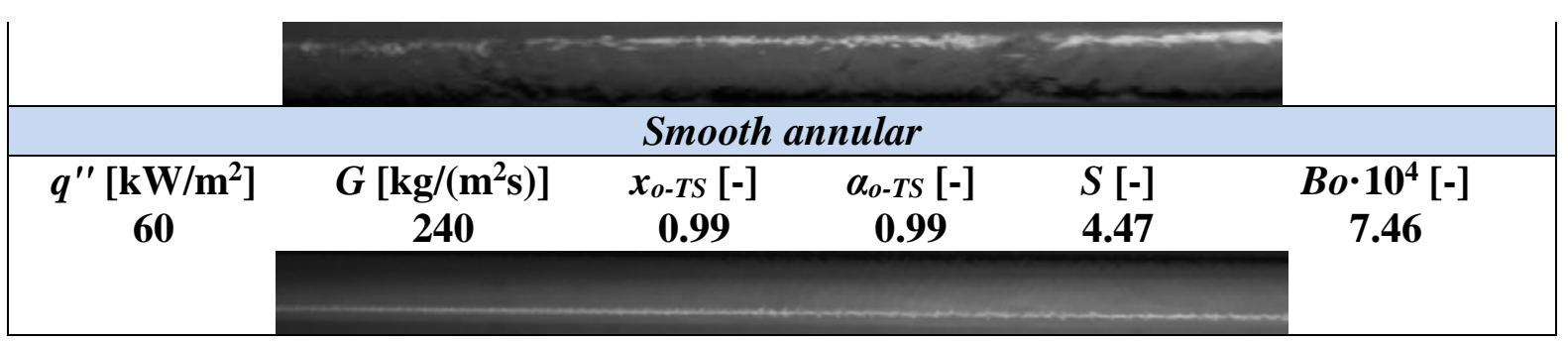

Figure 3. Two phase flow patterns observed during the tests.

The wavy-annular pattern is characterized by the presence of a liquid front wave sliding on the liquid-vapor interface in annular flow. Tibiriçá and Ribatski (2010) observed such pattern during flow boiling with R134a and R245fa. For $G=240 \mathrm{~kg} \mathrm{~m}^{-2} \mathrm{~s}^{-1}$, the wavy-annular was observed for all heat fluxes (except for $q{ }^{\prime}{ }_{T S}=5 \mathrm{~kW} / \mathrm{m}^{2}$ ) with $S$ ranging from 3.09 to 3.89 and $\alpha_{(o-T S)}$ between 0.72 and 0.8 . On the other hand, the 0.7 was the maximum $x_{(o-T S)}$ obtained in wavy-annular for $G=240 \mathrm{~kg} /\left(\mathrm{m}^{2} \mathrm{~s}\right)$ with $\alpha_{(o-T S)}=0.96$. The minimum $x_{(o-T S)}=0.44$ for wavyannular was observed in $G=480 \mathrm{~kg} \mathrm{~m}^{-2} \mathrm{~s}^{-1}$ with $\alpha_{(o-T S)}=0.88$ and $S=2.19$.

The smooth annular pattern was observed for $G=240$ and $320 \mathrm{~kg} /\left(\mathrm{m}^{2} \mathrm{~s}\right)$, but according to the results, only for 40 and $60 \mathrm{~kW} / \mathrm{m}^{2}$ in test section with highest heat condition in preheater. During the tests, smooth annular presented $S \geq 4.34$ and $0.98 \leq \alpha_{(o-T S)} \leq 0.99$ with minimum and maximum $x_{(o-T S)}$ between 0.95 and 0.99 .

Many flow pattern maps have been developed for both two-phase flow, both in adiabatic conditions and in convective boiling. For sake of clarity we merely employ a single flow pattern map in the present study, but like to mention the following ones that will be employed in a subsequent paper: Baker (1954); Taitel and Dukler (1976); Kattan et al. (1998); Wojtan et al. (2005); Revellin and Thome (2007); Barbieri et al. (2008); Cheng et al. (2008) and Mastrullo et al. (2012).

Ong and Thome (2011) published a study that focuses on investigating the transition from macro to microscale during flow boiling in small scale channels of three different sizes (1.03, 2.20 and $3.04 \mathrm{~mm}$ diameter) with three different refrigerants (R134a, R236fa and R245fa) over a range of saturation conditions to investigate the effects of channel confinement on two-phase flow patterns and liquid film stratification in a single circular horizontal channel. A flow pattern map has been proposed that includes new dimensionless numbers for considering the effects of gravity, inertia and surface tension and the determination of the flow patterns transitions. The gravity forces are suppressed and overcome by the surface tension and shear forces for microscale $(\mathrm{Co} \rightarrow 1.0)$. Isolated Bubble (IB) to Coalescent Bubble (CB) to Annular (A) (smooth and wavy) flow for microchannels were the patterns transitions in the map. Thus, in this work this map was used for data analysis, considering the microescale flow condition $(\mathrm{Co}=1.22)$ and flow patterns identified.

Fig. 4 presents the observed flow patterns plotted on the Ong and Thome (2011) flow pattern developed by for $q " s T=20 \mathrm{~kW} / \mathrm{m}^{2}$. It is possible to observe that such a map presents coherence in predicting isolated bubbles flow (bubbly flow) and coalescing bubbles flow (plug and slug flows). It can also be seen that wavy-annular and smooth-annular flows are well fit on annular region of the map. Although the churn flow is not predicted by the map, it is located in the transition line between coalescing bubbles and annular flow. 


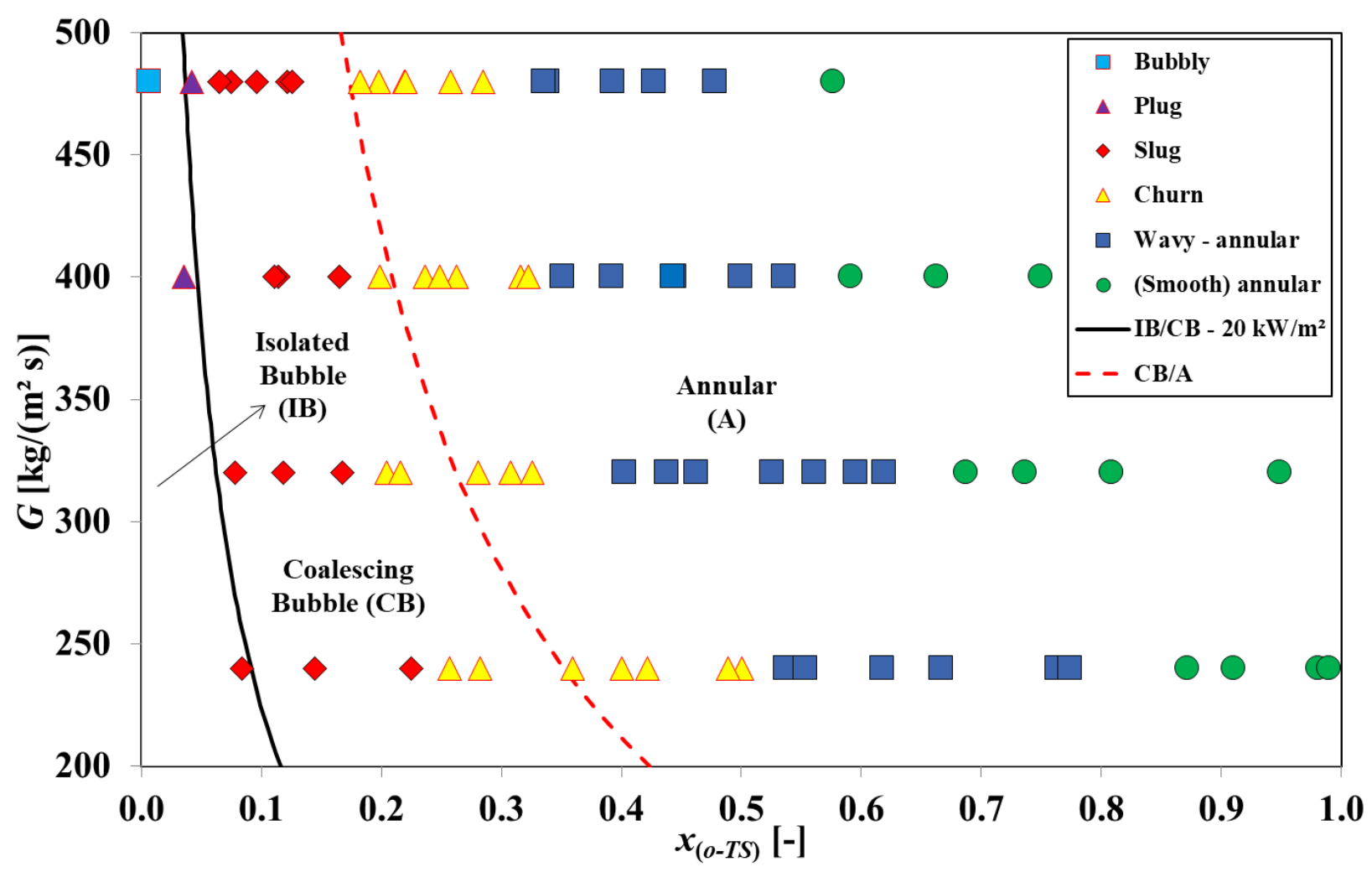

Figure 4. Comparison between Ong and Thome (2011) flow pattern map and flow patterns observed in the present investigation.

It is evident that the flow patterns present strong dependence on the mass flux and on applied heat flux. Both vapor quality and void fraction also have considerable influence on flow patterns since they affect the velocity of each phase. Thus, based on experimental results of the flow patterns obtained during the convective boiling of R-600a, R-290 and R-1270, a simple method of predicting flow patterns based on the influence of the parameters mentioned above is given by Eq. (12).

$$
\beta=S \cdot B o \cdot 10^{5}
$$

In fact, both heat and mass flux to the test section influence the generation of vapor quality and flow pattern at the exit, which justifies the presence of the Boiling number in $\beta$. Furthermore, the mean velocities of both phases both affect the morphology of the flow pattern. For this reason, the slip ratio is another important parameter in $\beta$. These mean velocities obviously also depend on the inlet quality. $ß$ was obtained through the analysis of a database with 80 points with all patterns observed, considering superficial velocity of each phase, vapor quality and void fraction as function of both mass and heat fluxes. Its specific form was obtained in order to avoid overlapping of flow patterns when presented as function of vapor quality or void fraction, as can be seen in Fig. 5 .

Table 4 presents the condition $\beta$ for each flow pattern based on the results of propane. Bubbly/plug flow is characterized by $\beta \leq 4$, but it is observed only when $\alpha<0.1$. On the other hand, plug is predominant for $\beta$ ranging from 4 to 10 , and for this condition, $0.4 \leq \alpha<0.5$. For $\beta$ ranging from 10 to 20, slug flow is found and it is ruled by a short variation of vapor quality between 0.11 and 0.13 . Because churn and wavy-annular correspond to the two most frequent patterns observed, $\beta$ presents the largest variations found: from 20 to 125 and 125 to 245, respectively. Finally, it is observed that smooth annular flow is found when $\beta \geq 245$. 


\begin{tabular}{cc}
\hline $\begin{array}{c}\text { Table } 4 \text { - Proposed variation of the parameter } \boldsymbol{\beta} \text { to } \\
\text { characterize flow pattern for } \mathrm{R}-290 .\end{array}$ \\
\hline Bubbly/plug & $\boldsymbol{\beta} \leq 4$ \\
Plug & $4<\boldsymbol{\beta}<10$ \\
Slug & $10<\boldsymbol{\beta}<20$ \\
Churn & $20<\boldsymbol{\beta}<125$ \\
Wavy-annular & $125<\boldsymbol{\beta}<245$ \\
Smooth-annular & $\beta \geq 245$ \\
\hline
\end{tabular}
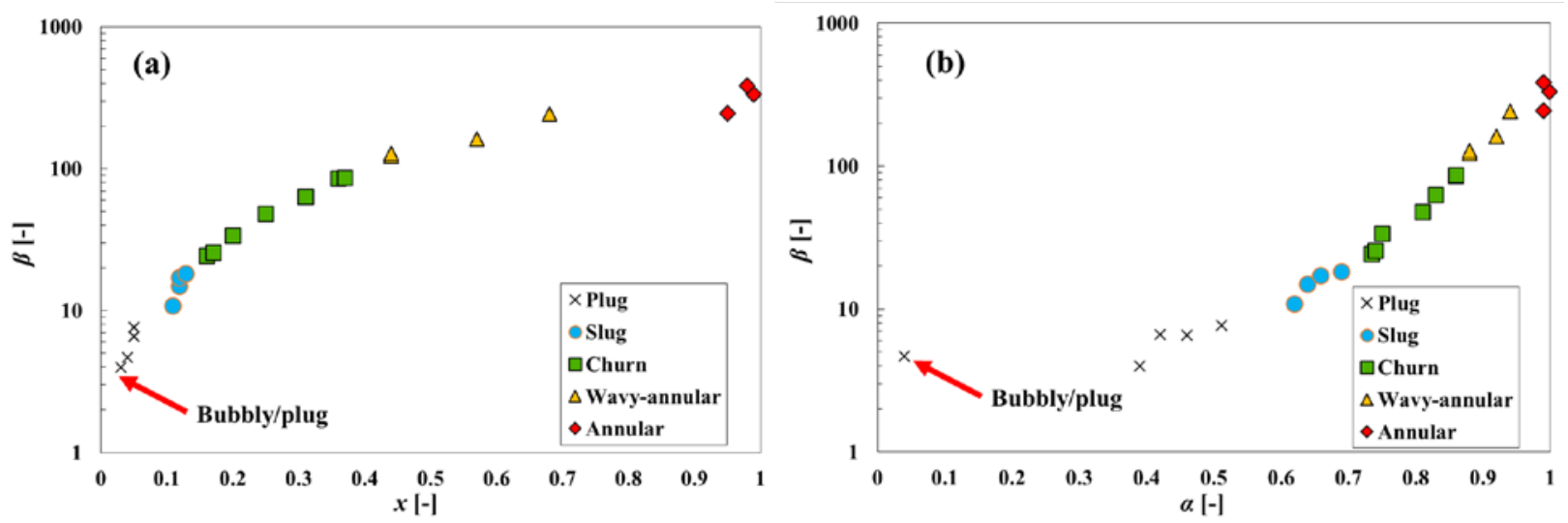

Figure 5. $\beta$ as a function of (a) vapor quality and (b) void fraction for propane.

\subsection{Heat Transfer}

\subsubsection{Heat flux effect}

The effect of the heat flux on the heat transfer coefficient is shown in Fig. 6. As it can be seen, the coefficient has a considerable dependence of the heat flux for all mass fluxes and vapor quality.

For $G=240$ and $320 \mathrm{~kg} /\left(\mathrm{m}^{2} \mathrm{~s}\right)$ with $q " T s \geq 20 \mathrm{~kW} / \mathrm{m}^{2}$, Figs. 6(a) and (b), heat transfer coefficient increases with increasing both heat flux and vapor quality, indicating a possible predominance of convective boiling in heat transfer. In fact, with the aid of images captured, it can be concluded that these coefficients are obtained, for the most part, in the region of transition between churn and wavy-annular flow, as well as in the region of smooth annular flow.

But for $q " T S \leq 10 \mathrm{~kW} / \mathrm{m}^{2}$, the heat transfer coefficient is almost constant and independent of vapor quality and it may indicate the predominance of nucleate boiling heat transfer phenomenon. In Figs. 6(a) and (b), the dry-out effect is observed for $q$ ” $T S=40$ e $60 \mathrm{~kW} / \mathrm{m}^{2}$ for $G$ $=240 \mathrm{~kg} /\left(\mathrm{m}^{2} \mathrm{~s}\right)$, and for $q$ " $T S=60 \mathrm{~kW} / \mathrm{m}^{2}$ in $G=320 \mathrm{~kg} /\left(\mathrm{m}^{2} \mathrm{~s}\right)$. As expected, the highest drop of heat transfer coefficient, caused by the drying of internal wall, was obtained with the highest heat flux and the lowest mass flux and the predominance of smooth annular flow.

For the cases where $G=400$ and $480 \mathrm{~kg} /\left(\mathrm{m}^{2} \mathrm{~s}\right)$, the heat transfer coefficient presents dependence on both the heat flux and the vapor quality, as shown in Figs. 6(c) and (d). In fact, especially for $G=480 \mathrm{~kg} /\left(\mathrm{m}^{2} \mathrm{~s}\right)$, it is observed that the heat transfer coefficient increases with the increase of these two parameters, even for $q^{\prime \prime} T S \leq 10 \mathrm{~kW} / \mathrm{m}^{2}$, where slug and churn patterns are 
predominant. Such characteristics of the heat transfer coefficient have already been observed by Wen et al. (2007) with tests involving R-290 and mixtures in circular tubes of $2.46 \mathrm{~mm}$.

\subsubsection{Mass flux effect}

Mass flux is one of the parameters that the most affects the process of heat transfer, mainly in convective boiling. The effect of mass flux on local heat transfer coefficient is presented in Figs. 7(a) and (b). The Fig. 7(a) shows the behavior of the local heat transfer coefficient for the lowest and highest heat fluxes $\left(10 \mathrm{~kW} / \mathrm{m}^{2}\right.$ and $\left.60 \mathrm{~kW} / \mathrm{m}^{2}\right)$ and mass fluxes $\left(240 \mathrm{~kg} /\left(\mathrm{m}^{2} \mathrm{~s}\right)\right.$ and 480 $\left.\mathrm{kg} /\left(\mathrm{m}^{2} \mathrm{~s}\right)\right)$ considered in this study. The experimental data show that local heat transfer coefficient increases with increasing the mass flux. And as the vapor quality increases, the effect of mass flux becomes more evident. In Fig. 7(b) it is presented the local heat transfer coefficient for mass fluxes equal to $240 \mathrm{~kg} /\left(\mathrm{m}^{2} \mathrm{~s}\right)$ and $320 \mathrm{~kg} /\left(\mathrm{m}^{2} \mathrm{~s}\right)$ for heat fluxes of 20 and $60 \mathrm{~kW} / \mathrm{m}^{2}$. In the case of $20 \mathrm{~kW} / \mathrm{m}^{2}$, the nucleate boiling contribution is observed for $x<0.20$. But in both graphics it is evident the predominance of convective boiling on heat transfer coefficient due the influence of heat flux. For similar conditions of mass and heat fluxes, Del Col et al. (2014) found higher heat transfer coefficients at a saturation temperature of $31{ }^{\circ} \mathrm{C}$. This also indicates that the heat transfer coefficient increases with increasing saturation temperature. Chávez et al. (2017) found a similar effect of mass flux on the heat transfer coefficient for a saturation temperature of $25{ }^{\circ} \mathrm{C}$ during flow boiling in a microchannels array heat sink.
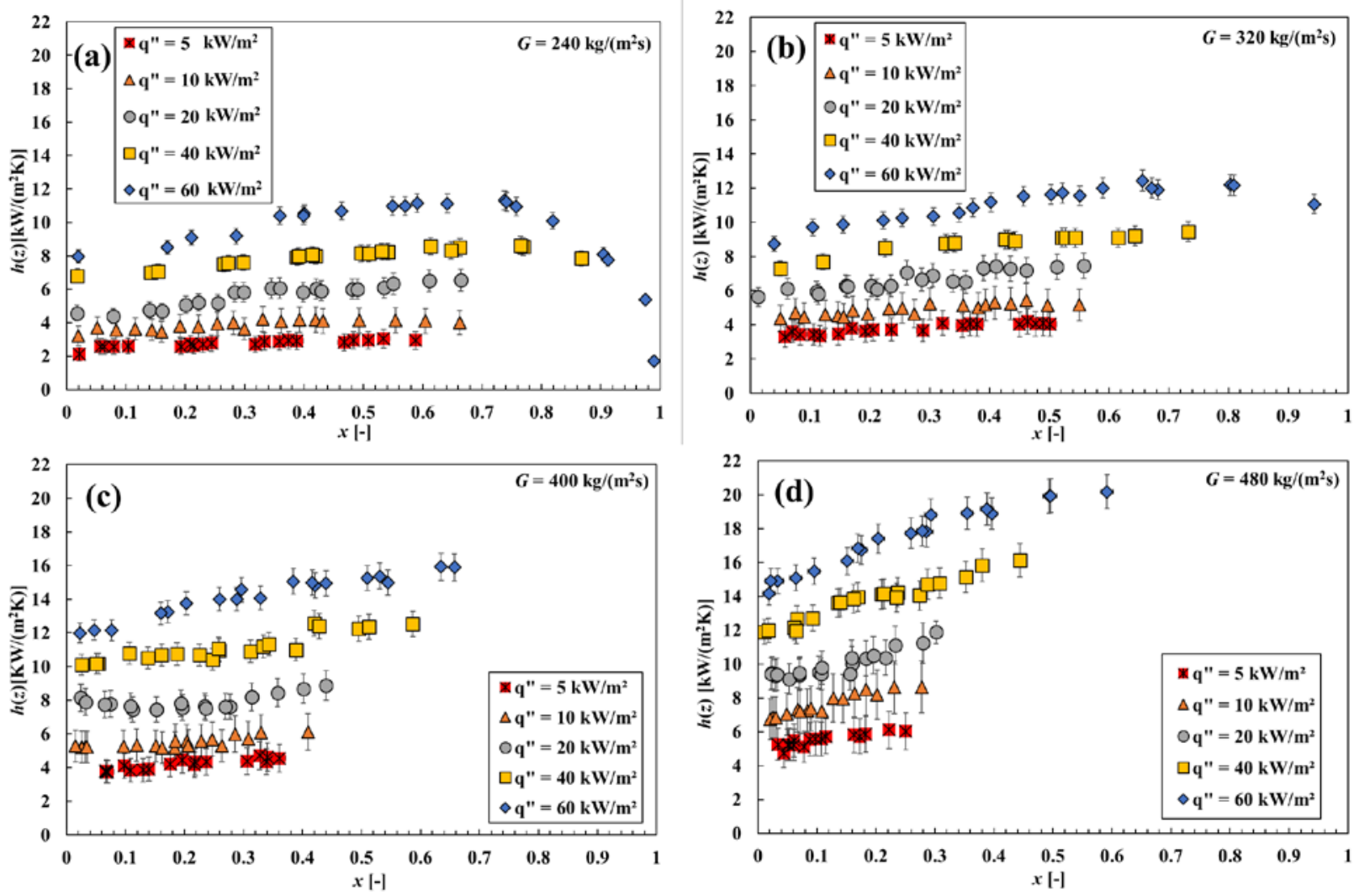

Figure 6. Local heat transfer coefficients versus vapor quality at constant mass fluxes:

(a) $240 \mathrm{~kg} /\left(\mathrm{m}^{2} \mathrm{~s}\right)$; (b) $320 \mathrm{~kg} /\left(\mathrm{m}^{2} \mathrm{~s}\right)$; (c) $400 \mathrm{~kg} /\left(\mathrm{m}^{2} \mathrm{~s}\right)$; (d) $480 \mathrm{~kg} /\left(\mathrm{m}^{2} \mathrm{~s}\right)$. 

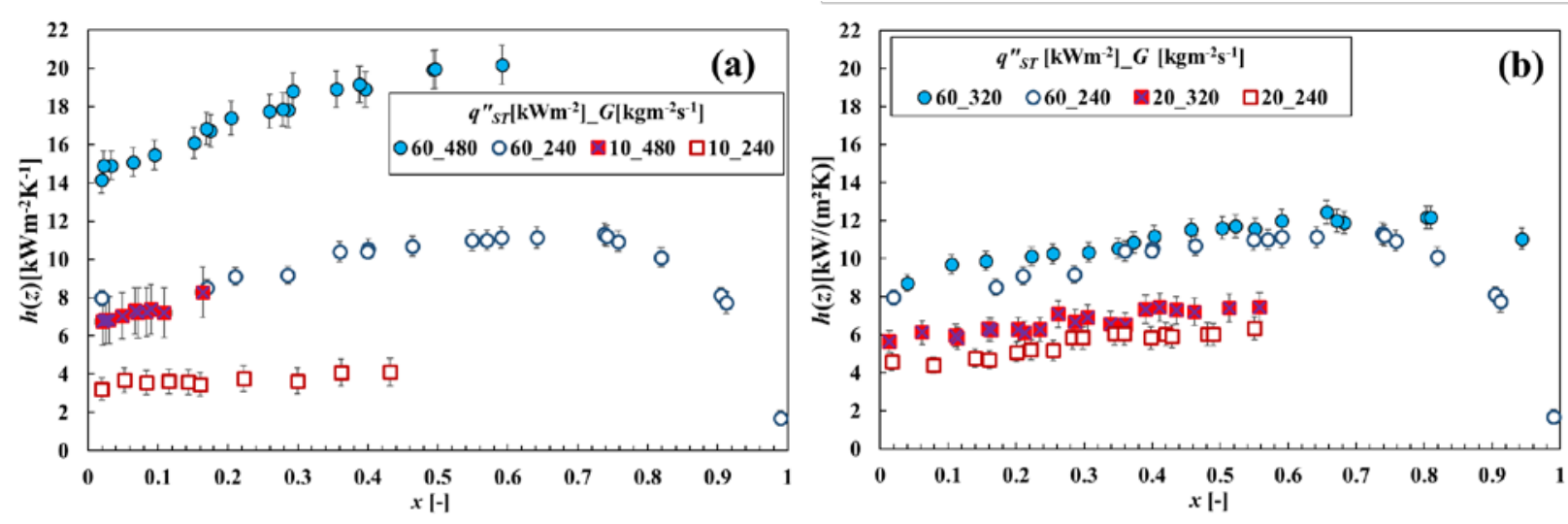

Figure 7. Effect of mass flux on local heat transfer coefficient: (a) For $G=240 \mathrm{~kg} /\left(\mathrm{m}^{2} \mathrm{~s}\right)$ and $480 \mathrm{~kg} /\left(\mathrm{m}^{2} \mathrm{~s}\right), q^{\prime}{ }_{T S}=10 \mathrm{~kW} / \mathrm{m}^{2}$ and $60 \mathrm{~kW} / \mathrm{m}^{2}$; (b) For $G=240 \mathrm{~kg} /\left(\mathrm{m}^{2} \mathrm{~s}\right)$ and $320 \mathrm{~kg} /\left(\mathrm{m}^{2} \mathrm{~s}\right)$, $q " T S=20 \mathrm{~kW} / \mathrm{m}^{2}$ and $60 \mathrm{~kW} / \mathrm{m}^{2}$.

Another way to analyze the influence of mass fluxes on heat transfer coefficient is by the boiling curve for different mass fluxes. The heat flux as function of wall superheat temperature, $T_{i w}-T_{\text {sat }}$, and the inlet vapor quality, $x_{(i-T S)}$, of 0.20 , is shown in Fig. 8. As the mass flux increases, the wall superheat decreases and the slope of each curve $\left(q\right.$ ” $\left.T S /\left(T_{i w}-T_{\text {sat }}\right)\right)$ increases, thus indicating the dependence of heat transfer coefficient on the mass flux. The dry-out effect is observed for $G=240 \mathrm{~kg} /\left(\mathrm{m}^{2} \mathrm{~s}\right)$, where the slope of the curve decreases between 40 and 60 $\mathrm{kW} / \mathrm{m}^{2}$, reaching a wall superheat temperature of $7.5{ }^{\circ} \mathrm{C}$. The decreasing on heat transfer coefficient associated to this effect is verified in Fig. 7b.

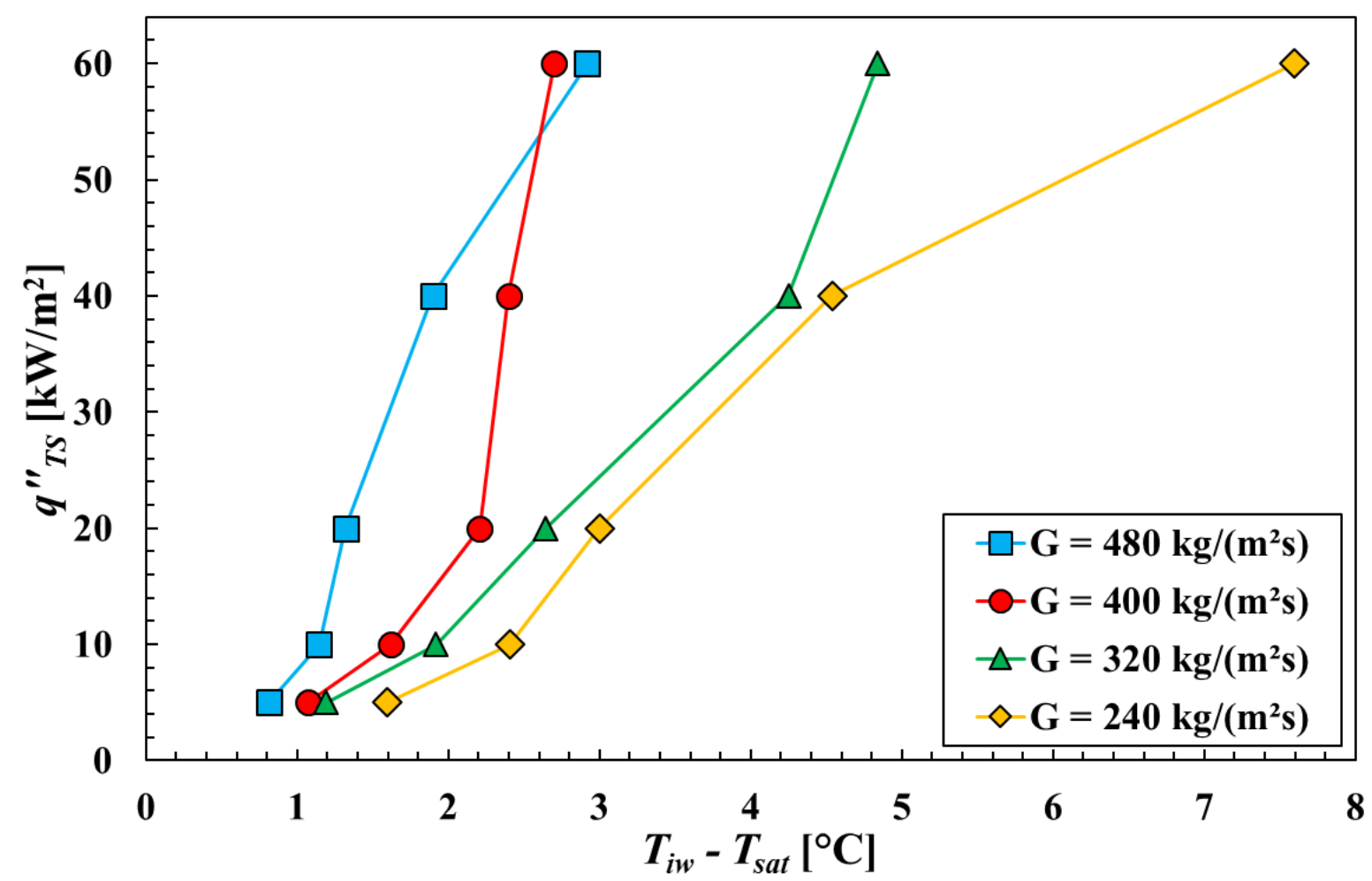

Figure 8. Boiling curves for $x_{(i-T S)}=0.20$ and different mass fluxes, $G$. 


\subsubsection{Effect of gravity}

The gravitational effect on the heat transfer coefficient is shown in Fig. 9 for the case of $G=$ $320 \mathrm{~kg} /\left(\mathrm{m}^{2} \mathrm{~s}\right)$ and $q{ }^{\prime}{ }_{T S}=60 \mathrm{~kW} / \mathrm{m}^{2}$. This result refers to the coefficients obtained at both top point and bottom point at position $z_{5}=263 \mathrm{~mm}$ of the test section for different heating conditions in the preheater. Although the error bars intersect, a tendency is observed indicating that the heat transfer coefficient in top point is higher than the coefficient obtained at the bottom point. This condition is obtained when $x_{-} \leq 0.8$ and the wave-annular pattern is predominant. This effect is probably caused by the variation of the thickness of the liquid film along the circumference of the tube, although it is not visually identified. Reduction in the thickness of the liquid film layer causes the thermal resistance of the liquid phase to decrease, thereby reducing the difference between the internal wall temperature and the saturation temperature. However, this tendency disappears when $x>0.9$, indicating a complete symmetry of liquid film around the tube. For the condition $x>0.8$, the dry-out effect is observed due to the decrease of both top and bottom heat transfer coefficient, as it can be seen in the curve of Fig. 6(b), for the same conditions of $G$ and $q$ ”. In fact, such behavior is observed for all mass fluxes and heat fluxes, but the difference of heat transfer coefficients increases for decreasing vapor quality and heat flux. Not only data for lower heat fluxes and mass fluxes as those in Fig. 9 have been examined, but also data for vapor qualities below 0.6. The same trend, an increasing difference in $\mathrm{h}$ for decreasing fluxes or quality, has been found. This trend is observed even in conditions of churn, slug and plug flow.

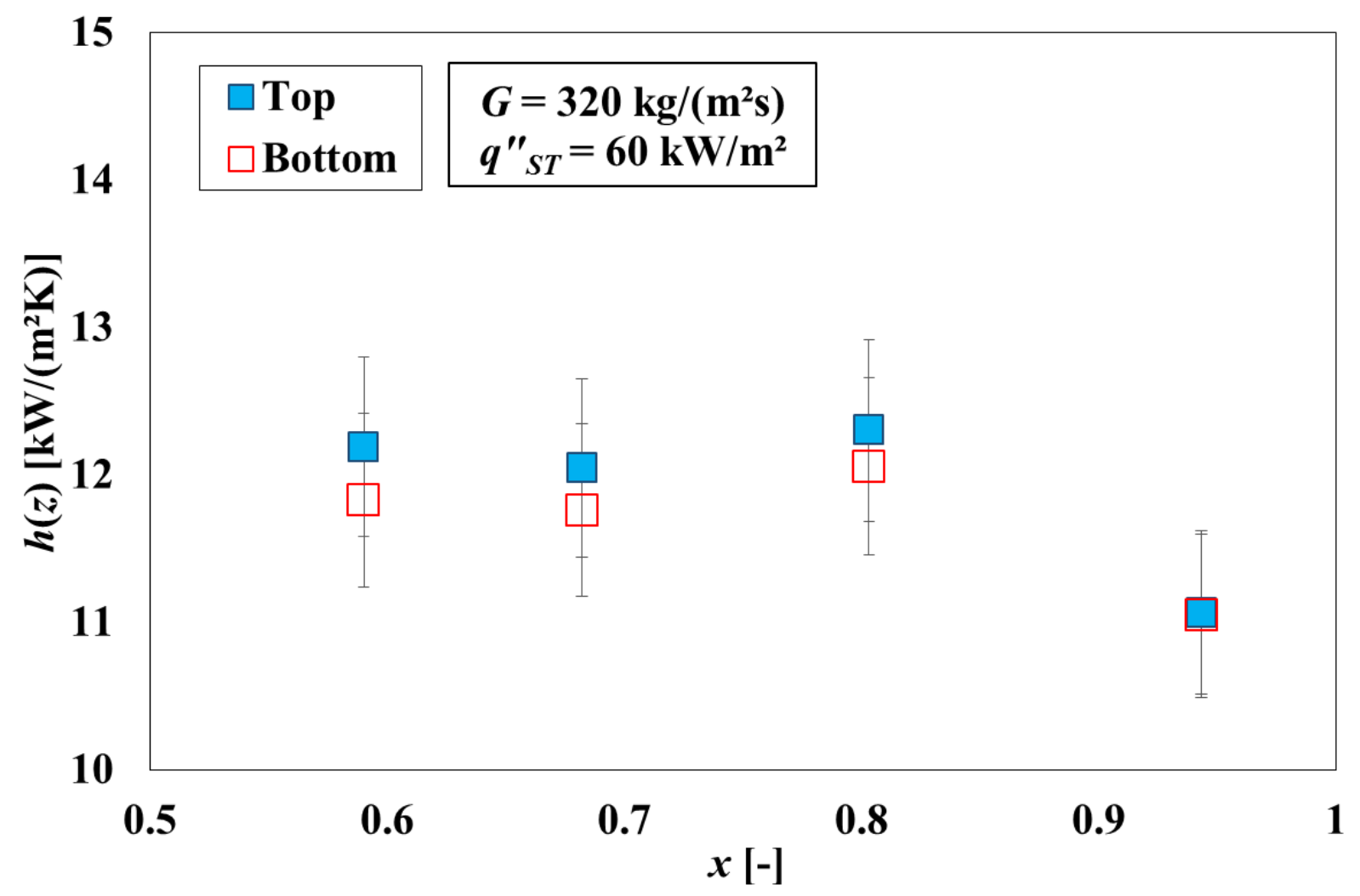

Figure 9. Difference between both heat transfer coefficient of the top and bottom points at the position $z_{5}$ in the test section.

\subsubsection{Comparison of experimental results with correlation for heat transfer}

Heat transfer results have been compared against six different correlations developed for flow boiling heat transfer coefficient in small channels: Kew and Cornwell (1997), Kandlikar and Balasubramanian (2004), Bertsch et al. (2009), Sun and Mishima (2009), Li and Wu (2010), 
Kim and Mudawar (2013), Mahmoud and Karayiannis (2013) and Sempértegui-Tapia and Ribatski (2017).

A study on R-141b during flow boiling in saturation temperature of $32{ }^{\circ} \mathrm{C}$ was developed by Kew and Cornwell (1997) with inner diameter between $1.39 \mathrm{~mm}$ and $3.69 \mathrm{~mm}$. The authors proposed a modification in the correlation of Lazarek and Black (1982) due the increase in heat transfer coefficient with vapor quality during their tests

Based on results from flow boiling of R-113, R-134, R-123, R-141b and water, Kandlikar and Balasubramanian (2004) proposed a modification of the correlation developed by Kandlikar (1990), taking into account effects related to inner diameter ranging from $0.19 \mathrm{~mm}$ and $2.59 \mathrm{~mm}$. The authors suggest a specific value for the fluid-surface parameter for each fluid studied in their investigation. For fluids not include in the correlation, they suggest the use of the fluid-surface parameter equal to one.

Sun and Mishima (2009) proposed a correlation based on correlation of Lazarek and Black (1982). It is based on a database with 2505 data points with eleven different working fluids for mass fluxes ranging from 44 to $1500 \mathrm{~kg} /\left(\mathrm{m}^{2} \mathrm{~s}\right)$ and hydraulic diameters between 0.21 and 6.5 $\mathrm{mm}$. Taking into account the trends in the experimental data, it was observed that the heat transfer coefficient was strongly dependent on Weber number, which is the ratio of fluid's inertia to the surface tension.

Bertsch et al. (2009) proposed a correlation based on Chen's (1966) model for flow boiling in mini and microchannels. Their correlation was developed based on a database about experiments with hydraulic diameters ranging from $0.16 \mathrm{~mm}$ to $2.92 \mathrm{~mm}$, heat flux between 4 and $1150 \mathrm{~kW} / \mathrm{m}^{2}$, mass flux ranging from 20 to $3000 \mathrm{~kg} /\left(\mathrm{m}^{2} \mathrm{~s}\right)$. Twelve different refrigerants were used, with saturation temperature ranging from $-194{ }^{\circ} \mathrm{C}$ to $97{ }^{\circ} \mathrm{C}$. One of the main characteristics of such correlation is that the enhancement factor $F$ is strongly influenced by the confinement of bubbles in small channels.

$\mathrm{Li}$ and $\mathrm{Wu}$ (2010) proposed a correlation that covered experimental studies related to saturation flow boiling heat transfer in micro and mini-channels using thirteen different refrigerant fluids including propane for mass fluxes between 20.3 and $3570 \mathrm{~kg} /\left(\mathrm{m}^{2} \mathrm{~s}\right)$ and hydraulic diameters ranging from 0.16 to $3.0 \mathrm{~mm}$. To consider the effects of small hydraulic diameter, the authors introduced both the Bond number and Reynolds number of liquid phase. According to them, the relationship of two non-dimensional parameters presents the influence of body force, surface tension, viscous force and inertia force in saturation flow boiling in reduce channels.

Kim and Mudawar (2013) developed a correlation for pre-dryout saturated flow boiling in mini and micro-channels in both single- and multi-channel configurations. Their correlation is based on a database of 10,805 experimental data points with eighteen different working fluids and hydraulic diameter ranging from 0.19 to $6.5 \mathrm{~mm}$ and mass fluxes between 19 and 1608 $\mathrm{kg} /\left(\mathrm{m}^{2} \mathrm{~s}\right)$.

Mahmoud and Karayiannis (2013) proposed a correlation based on an experimental database of flow boiling of R-134a with 5152 data points and tubes with internal diameter ranging from 0.52 to $4.26 \mathrm{~mm}$. Their correlation encompasses modifications of both the nucleate boiling suppression factor and the convective boiling enhancement factor, based on the analogy between heat and momentum transfer in the boundary layer as a function of the confinement number.

Sempértegui-Tapia and Ribatski (2017) proposed a modification of the correlation developed by Kanizawa et al. (2016b), based on an experimental study of flow boiling for R-134a, R1234ze(E), R-1234yf and R-600a in a small channel of $1.1 \mathrm{~mm}$.

Statistical analysis using mean bias error $(M B E)$, which indicates the variation of the calculated values with respect to measured ones, and root mean square error (RMSE), which indicates the dispersion of the regression, were implemented to evaluate the performance of the predicted models. The comparisons of experimental heat transfer coefficient with predictions are presented in Fig. 10. The results considering such parameters and fraction of date within $\pm 35 \%$, or DPEB, are presented in Tab. 5. 
Despite the fact that the Sempértegui-Tapia and Ribatski (2017) correlation was developed specially for hydrocarbon, the statistical results indicate that the model developed by Li and Wu (2010) presents the best fit, followed by Sempértegui-Tapia and Ribatski (2017). On the other hand, Kew and Cornwell (1997) and Kandlikar and Balasubramanian (2004) models, for example, yield considerable discrepancies between experimental and predicted data. For this reason, it is convenient to analyze the behavior of the correlations with experimental heat transfer coefficient. The Fig. 11 presents the correlations as function of vapor quality based on the specific conditions. For $G=240 \mathrm{~kg} /\left(\mathrm{m}^{2} \mathrm{~s}\right)$ and $q " T s=60 \mathrm{~kW} / \mathrm{m}^{2}$, Fig. 11 (a), Bertsch et al. (2009) model presents the best behavior when compared to experimental data along the range of vapor quality. A similar trend can be observed with Sempértegui-Tapia and Ribatski (2017) correlation, including the occurrence of dry-out effect. The increase of heat transfer coefficient with increasing vapor quality is well predicted by Kew and Cornwell (1997) although it is unable to indicate the presence of dry-out. On the other hand, the correlations proposed by Sun and Mishima (2009), Li and Wu (2010) and Kim and Mudawar (2013) predict heat transfer coefficient practically constant along the range of vapor quality. Finally, Kandlikar and Balasubramanian (2004) correlation overestimates and underestimates the heat transfer coefficient in nucleate boiling and convective boiling predominance regions, respectively.

For $G=400 \mathrm{~kg} /\left(\mathrm{m}^{2} \mathrm{~s}\right.$ ) and $q " T S=40 \mathrm{~kW} / \mathrm{m}^{2}$ (Fig. 11(b)), it can be seen that Kew and Cornwell (1997), Bertsch et al. (2009) and Kim and Mudawar (2013) models follow the trend of the experimental heat transfer coefficient with the increase of vapor quality. However, the correlations proposed by Sun and Mishima (2009) and Li and Wu (2010) and Sempértegui-Tapia and Ribatski (2017) follow with some precision the experimental heat transfer coefficient for $x<$ 0.35. On the other hand, Kew and Cornwell (1997) correlation is more accurate for $x>0.4$. Moreover, Kandlikar and Balasubramanian (2004) correlation keeps the trend of overestimating and underestimating the heat transfer coefficient with the increase of vapor quality.

Another condition analyzed is related to $G=480 \mathrm{~kg} /\left(\mathrm{m}^{2} \mathrm{~s}\right)$ and $q$ " $T S=5 \mathrm{~kW} / \mathrm{m}^{2}$, presented in Fig. 11(c). For that case, Kew and Cornwell (1997) and Sempértegui-Tapia and Ribatski (2017) present the lowest variation between experimental and predicted values. Since the correlations proposed by Bertsch et al. (2009), Sun and Mishima (2009) and Kim and Mudawar (2013) underestimate the heat transfer coefficient. In contrast, Kandlikar and Balasubramanian (2004) correlation overestimates along the variation of vapor quality. 

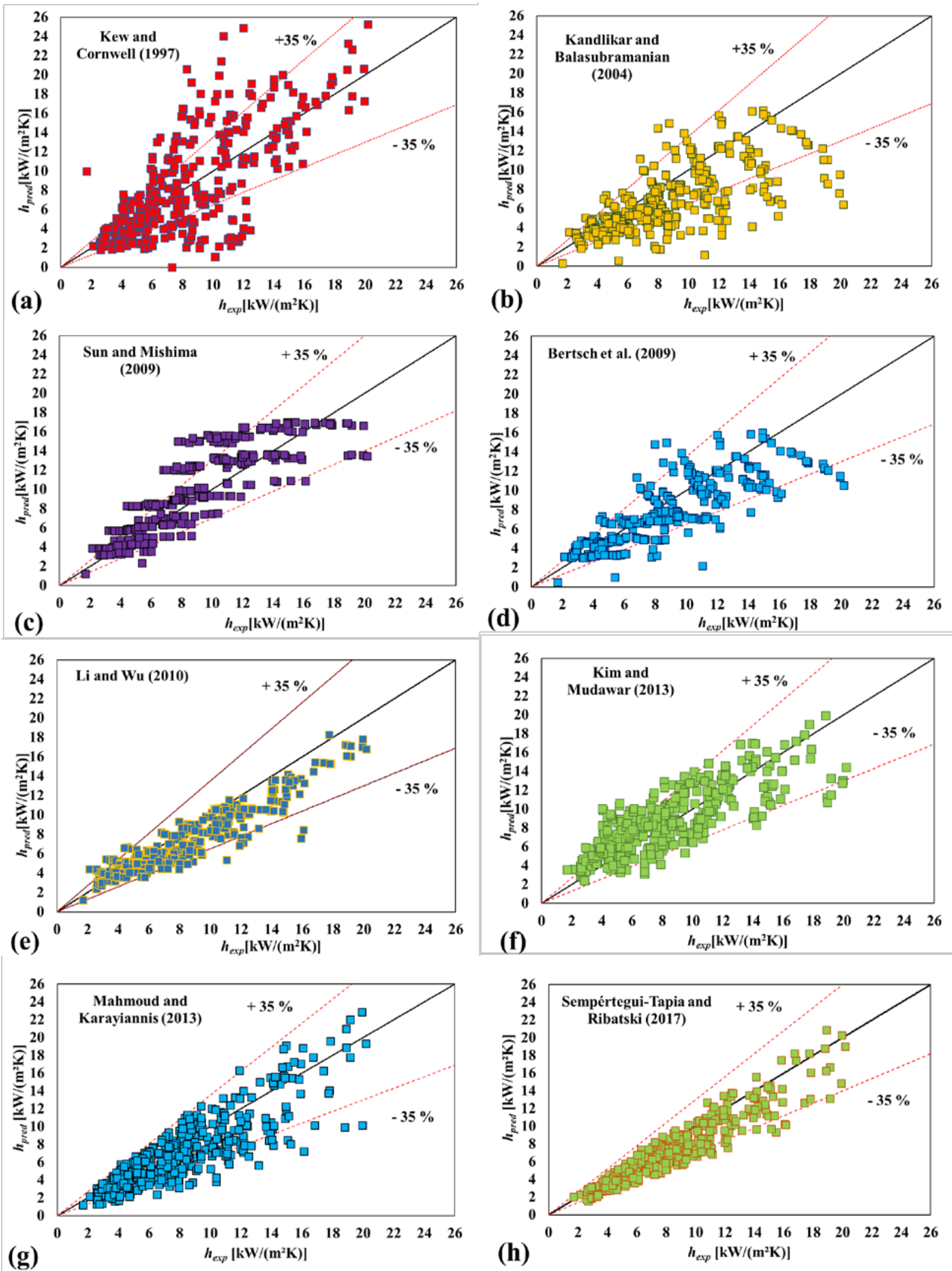

Figure 10. Experimental versus predicted heat transfer coefficient applying different correlations:

(a) Kew and Cornwell (1997), (b) Kandlikar Balasubramanian (2004), (c) Sun and Mishima (2009), (d) Bertsch et al. (2009), (e) Li and Wu (2010), (f) Kim and Mudawar (2013), (g) Mahmoud and Karayiannis (2013) and (h) Sempértegui-Tapia and Ribatski (2017). 
Table 5 - Statistical results of comparison of heat transfer coefficient.

\begin{tabular}{cccc}
\hline Author & MBE (\%) & RMSE (\%) & DPEB (\%) \\
Kew and Cornwell (1997) & 16.4 & 48.58 & 59 \\
Kandlikar and Balasubramanian (2004) & $-\mathbf{1 6 . 1}$ & 31.2 & 61.8 \\
Sun and Mishima (2009) & 15.2 & 30.5 & 88.5 \\
Bertsch et al. (2009) & -6.64 & 25.25 & 90.3 \\
Li and Wu (2010) & -8.5 & 20.8 & 97.8 \\
Kim and Mudawar (2013) & 16.01 & 37.82 & 78 \\
Mahmoud and Karayiannis (2013) & -14.8 & 39.04 & 69.1 \\
Sempértegui-Tapia and Ribatski (2017) & -9.8 & 23.4 & 94.2 \\
\hline
\end{tabular}



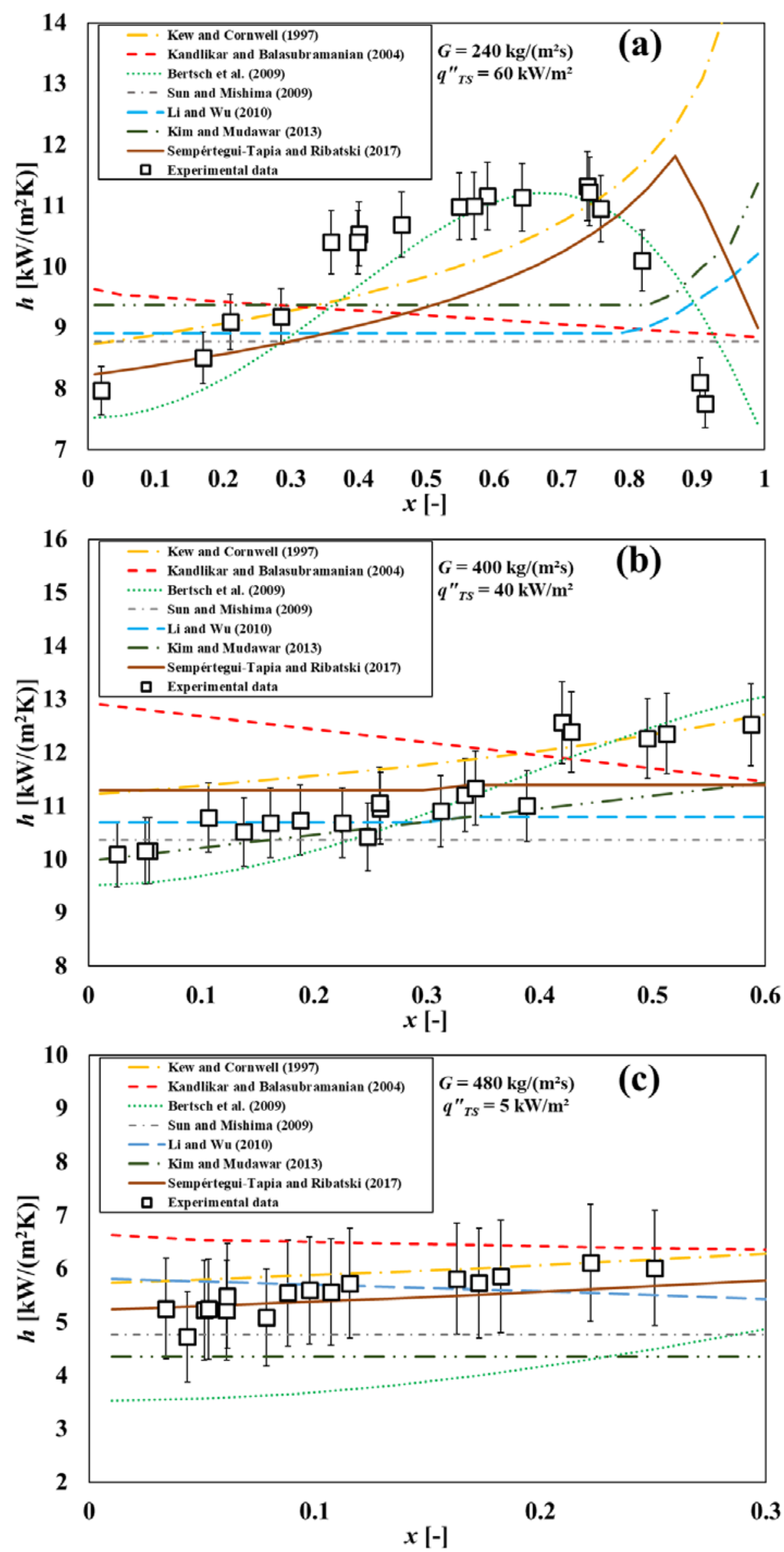

Figure 11. Comparison between some experimental and predicted results as function of vapor quality for different conditions of both mass and heat transfer. 


\section{CONCLUSION}

An experimental study on flow patterns and boiling heat transfer of R-290 was performed with a horizontal circular tube of $1.0 \mathrm{~mm}$ inner diameter for various mass fluxes and heat fluxes at constant saturation temperature of $25^{\circ} \mathrm{C}$. The main findings are the following:

- The two-phase flow pattern observations have shown a dominance of slug, churn, wavyannular and smooth-annular flow regimes. Plug/bubbly and plug flows were observed only during lower vapor quality conditions, indicating that such patterns are related to nucleate boiling dominance.

- A simple method to identify the flow pattern based on boiling number and slip ratio is proposed.

- The heat transfer coefficient is highly dependent on both mass velocity and heat flux.

- It was observed the occurrence of dryout, even for lower mass velocities and higher heat flux conditions.

- The heat transfer coefficient increases with increasing vapor quality.

- Among the correlations used to predict the heat transfer coefficient in this investigation, Li and Wu (2010) correlation, followed by Sempértegui-Tapia and Ribatski (2017) satisfactorily presented the best fit when compared with experimental data.

\section{ACKNOWLEDGEMENTS}

This research project was financially supported by the Brazilian National Council of Research (CNPq), through the project 162620/2015-2 and by PETROBRAS/ANEEL, through the project PD-0553-0023/2012.

\section{Appendix A}

\section{Analysis of the combined standard uncertainty}

The combined standard uncertainty was used to establish the uncertainty of each parameter measured (external temperature, mass flow, absolute and differential pressures) and calculated (heat flux, internal and saturation temperatures, mass flux, heat transfer coefficient, vapor quality such as thermodynamics and transport properties). A methodology used to calibrate and stablish the combined standard uncertainty of thermocouples, proposed by Oliveira et al. (2015), was implemented in this experiment.

The combined standard uncertainty in heat flux, based on Eq. (1), is given by

$$
u\left(q^{\prime \prime}\right)=\sqrt{\left(\frac{\partial q^{\prime \prime}}{\partial U} d U\right)^{2}+\left(\frac{\partial q^{\prime \prime}}{\partial I} d I\right)^{2}+\left(\frac{\partial q^{\prime \prime}}{\partial A_{H}} d A_{H}\right)^{2}}
$$

where $d U, d I$ and $d A_{H}$ represent the uncertainties of voltage, electric current and heated area presented in Table 3.

The combined standard uncertainty in internal wall is given by the following equation, based on Eqs. (2), ignoring uncertainty related to thermal conductivity of stainless steel.

$$
u\left(\bar{T}_{i w}(z)\right)=\sqrt{\left(\frac{\partial \bar{T}_{i w}(z)}{\partial \bar{T}_{e w}(z)} d \bar{T}_{e w}(z)\right)^{2}+\left(\frac{\partial \bar{T}_{i w}(z)}{\partial \dot{q}_{T S}} d \dot{q}_{T S}\right)^{2}+\left(\frac{\partial \bar{T}_{i w}(z)}{\partial r_{e}} d r_{e}\right)^{2}+\left(\frac{\partial \bar{T}_{i w}(z)}{\partial r_{i}} d r_{i}\right)^{2}}
$$


Since the saturation temperature is assumed to be a linear function of saturation pressure, it can be described as Eq. (A3).

$T_{\text {sat }}(z)=a \cdot p_{\text {sat }}+b$

The coefficients $a$ and $b$ were obtained considering a linear regression between $24^{\circ} \mathrm{C}$ and $26{ }^{\circ} \mathrm{C}(928.2 \mathrm{kPa}$ and $976.7 \mathrm{kPa})$. So, the uncertainty in saturation temperature is given by Eq. (A4).

$d T_{\text {sat }}(z) \equiv u\left(T_{\text {sat }}(z)\right)=a \cdot d p_{\text {sat }}$

where $d p_{\text {sat }}$ is assumed to be equal to the uncertainty of absolute pressure transducer in the inlet of test section.

Consequently, the combined standard uncertainty in local heat transfer coefficient is defined according to

$u(h(z))=\sqrt{\left(\frac{\partial h(z)}{\partial q^{\prime \prime}} d q^{\prime \prime}\right)^{2}+\left(\frac{\partial h(z)}{\partial T_{i w}(z)} d T_{i w}(z)\right)^{2}+\left(\frac{\partial h}{\partial T_{\text {sat }}} d T_{\text {sat }}\right)^{2}}$

Li et al. (2012), Del Col et al. (2013) and Charnay et al. (2015) present similar uncertainty analysis of heat transfer coefficient.

The vapor quality in each location has its combined standard uncertainty related to local enthalpy and the enthalpy of liquid and vapor phases, as

$u(x(z))=\sqrt{\left(\frac{\partial x(z)}{\partial i(z)} d i(z)\right)^{2}+\left(\frac{\partial x(z)}{\partial i_{l}} d i_{l}\right)^{2}+\left(\frac{\partial x(z)}{\partial i_{v}} d i_{v}\right)^{2}}$

where $\operatorname{di}(z)$ is obtained by solving the combined standard uncertainty from Eq. (8). Similarly, to saturation temperature, $d i_{l}$ and $d i_{v}$ are considered as functions of saturation pressure and are given by the following equations

$$
\begin{aligned}
& d i_{l} \equiv u\left(i_{l}\right)=c \cdot d p_{s a t} \\
& d i_{v} \equiv u\left(i_{v}\right)=d \cdot d p_{s a t}
\end{aligned}
$$

\section{REFERENCES}

Anwar, Z., Palm, B., Khodabandeh, R., 2015. "Flow Boiling Heat Transfer and Dryout Characteristics of R600a in a Vertical Minichannel”. Heat transfer Engineering, Vol. 36 (14 15), pp. $1230-1240$.

Apaydin, T., Heperkan, H., 2016. "Experimental investigation of R-600a refrigerant flow inside adiabatic capillary tube”. Sigma Journal Engineering and Natural Sciences, Vol. 34(2), pp. 241 $-252$.

Aprin, L., Mercier, P., Tadrist, L., 2011. "Local heat transfer analysis for boiling of hydrocarbons in complex geometries: A new approach for heat transfer prediction in staggered tube bundle”. International Journal of Heat and Mass Transfer, Vol. 54, pp. 4203-4219. 
Baker, O., 1954. "Design of pipe lines for simultaneous flow of oil and gas". Oil and Gas Journal, Vol. 53, pp. $185-190$.

Barbieri, P., Jabardo, J., Bandarra Filho, E., 2008. "Flow patterns in convective boiling of refrigerant R-134a in smooth tubes of several diameters", in: Proceedings of the 5th European Thermal-Sciences Conference, Eindhoven, The Netherlands.

Bertsch, S. S., Groll, E. A., Garimella, S. V., 2009. “A composite heat transfer correlation for saturated flow boiling in small channels". International Journal of Heat and Mass Transfer, Vol. 52, pp. $2110-2118$.

Brutin, D., Tadrist, L., 2004. "Pressure drop and heat transfer analysis of flow boiling in a minichannel: Influence of the inlet condition on two-phase flow stability". International Journal of Heat and Mass Transfer, Vol. 47, pp. 2365 - 2377.

Charnay, R., Revellin, R., Bonjour, J., 2015. "Flow boiling heat transfer in minichannels at high saturation temperatures: part I - experimental investigation and analysis of the heat transfer mechanisms”. International Journal of Heat and Mass Transfer, Vol. 87, pp. 636 - 652.

Chávez, C.A., Leão, H.L.S.L., Ribatski, G. "Evaluation of thermal-hydraulic performance of hydrocarbon refrigerants during flow boiling in a microchannels array heat sink". Applied Thermal Engineering. Vol. 111, pp. 703 - 717.

Chen, D., Shi, Y., 2013. “Two-phase heat transfer and pressure drop of LNG during saturated flow boiling in a horizontal tube”. Cryogenics (Guildf), Vol. 58, pp. 45 - 54.

Chen, G.M., Zhelezny, V.P., Melnyk, A.V., Shestopalov, K.O., 2015. “An experimental investigation and modelling of flow boiling heat transfer of isobutane-compressor oil solution in a horizontal smooth tube”. International Journal of Refrigeration, Vol. 58, pp. 137 - 145.

Chen, J.C., 1966. "Correlation for boiling heat transfer to saturated fluids in convective flow”. Industrial \& Engineering Chemistry Process Design and Development, Vol. 5, pp. 322 339.

Cheng, L., Ribatski, G., Quibèn, J.M., Thome, J.R., 2008. "New prediction methods for $\mathrm{CO}_{2}$ evaporation inside tubes: Part I - A two-phase flow pattern map and a flow pattern based phenomenological model for two-phase flow frictional pressure drops”. International Journal of Heat and Mass Transfer, Vol. 51(1-2), pp. 111-124.

Choi, K-. I., Pamitran, A.S., Oh, J-.T., Saito, K., 2009. "Pressure drop and heat transfer during two-phase flow vaporization of propane in horizontal smooth minichannels". International Journal of Refrigeration, Vol. 32, pp. $837-845$.

Copetti, J.B., Macagnan, M.H., Zinani, F., 2013. "Experimental study on R-600a boiling in 2.6 mm tube”. International Journal of Refrigeration, Vol. 36, pp. 325 - 334.

Del Col, D., Bortolin, S., Torresin, D., Cavallini, A., 2013. “Flow boiling of R1234yf in a $1 \mathrm{~mm}$ diameter channel”. International Journal of Refrigeration, Vol. 36, 353 - 362.

Del Col, D., Bortolato, M., Bortolin, S., 2014. "Comprehensive experimental investigation of two- phase heat transfer and pressure drop with propane in a minichannel”. International Journal of Refrigeration, Vol. 47, pp. $66-84$. 
Del Col, D. Azzolin, M., Bortolin, S., Berto, A., 2017. "Experimental results and design procedures for minichannel condensers and evaporators using propylene”. International Journal of Refrigeration. Vol. 83, pp. 23 - 38.

Dittus, F.W., Boelter, L.M.K., 1930. University of California Publications on Engineering, Vol. 2, pp. 433.

Gnielinski, V., 1976. "New equations for heat and mass transfer in turbulent pipe and channel flow”. International Chemical Engineering, Vol. 16, pp. 359 - 368.

He, G., Liu, F., Cai, D., Jiang, J., 2016. "Experimental investigation on flow boiling heat transfer performance of a new near azeotropic refrigerant mixture R290/R32 in horizontal tubes”. International Journal of Heat and Mass Transfer, Vol. 102, pp. 561 - 573.

Kandlikar, S. G., 1990. “A general correlation for two-phase flow boiling heat transfer coefficient inside horizontal and vertical tube”. Journal of Heat Transfer, Vol. 102, pp. 219 228.

Kandlikar, S. G., Balasubramanian, P., 2004. "An extension of the flow boiling correlation to transition, laminar, and deep laminar flows in minichannels and microchannels". Heat Transfer Engineering, Vol. 25(3), pp. 86 - 93.

Kanizawa, F.T., Tibiriçá, C.B., Ribatski, G., 2016a. "Heat transfer during convective boiling inside microchannels”. International Journal of Heat and Mass Transfer, Vol. 93, pp. 566 - 583.

Kanizawa, F.T., Mogaji, T.S., Ribatski, G., 2016b. “A new model for flow boiling heat transfer coefficient inside horizontal tubes with twisted-tape inserts". International Journal of Refrigeration, Vol. 61, pp. 55 - 68.

Kattan, N., Thome, J.R., Favrat, D., 1998. "Flow boiling in horizontal tubes. Part 1: Development of a diabatic two-phase flow pattern map”. International Journal of Heat Transfer, Vol. 120(1), pp. 140 - 147.

Kew, P. A., Cornwell, K., 1997. "Correlations for the prediction of boiling heat transfer in smalldiameter channels”. Applied Thermal Engineering, Vol. 17(8-10), pp. 705 - 715.

Kim, S-.M., Mudawar, I., 2013. "Universal approach to predicting saturated flow boiling heat transfer in mini/micro-channels - Part II. Two-phase heat transfer coefficient”. International Journal of Heat and Mass Transfer, Vol. 64, pp. 1239 - 1256.

Lazarek, G.M., Black, S.H., 1982. "Evaporative heat transfer, pressure drop and critical heat flux in a small vertical tube with R-113”. International Journal of Heat and Mass Transfer, Vol. 25, pp. $945-960$.

Lee, H.S., Yoon, J.I., Kim, J.D., Bansal, P., 2005. "Evaporating heat transfer and pressure drop of hydrocarbon refrigerants in 9.52 and $12.70 \mathrm{~mm}$ smooth tube”. International Journal of Heat and Mass Transfer, Vol. 48, pp. $2351-2359$.

Lemmon, E. W., Hube, M. L., Mclinden, M. O., Physics and Chemical Properties Division, REFPROP 9.1, NIST Standard Reference Database 23, Version 9.1. 
Li, M., Dang, C., Hihara, E., 2012. "Flow boiling heat transfer of HFO1234yf and R32 refrigerant mixtures in a smooth horizontal tube: part I. Experimental investigation". International Journal of Heat Mass Transfer, Vol. 55, pp. 3437 - 3446.

Li, W., Wu, Z., 2010. "A general correlation for evaporative heat transfer in micro/minichannels”. International Journal of Heat and Mass Transfer, Vol. 53, pp. 1778 - 1787.

Maqbool, M.H., Palm, B., Khodabandeh, R., 2013. "Investigation of two phase heat transfer and pressure drop of propane in a vertical circular minichannel”. Experimental Thermal and Fluid Science, Vol. 46, pp. 120 - 130.

Mashouf, H., Shafaee, M., Sarmadiam, A., Mohseni, S.G., 2017. "Visual study of flow patterns during evaporation and condensation of R-600a inside horizontal smooth and helically dimpled tubes”. Applied Thermal Engineering, Vol. 124, pp. 1392 - 1400.

Mastrullo, R., Mauro, A.W., Thome, J.R., Toto, D., Vanoli, G.P., 2012. "Flow pattern maps for convective boiling of $\mathrm{CO}_{2}$ and $\mathrm{R} 410 \mathrm{~A}$ in a horizontal smooth tube: Experiments and new correlations analyzing the effect of the reduced pressure”. International Journal of Heat and Mass Transfer, Vol. 55, pp. 1519 - 1528.

Mikielewicz, D., Jakubowska, B., 2015. "Measurement and correlation of flow boiling heat transfer of R600a/compressor oil solution inside a horizontal smooth tube”. Holodil'naâ Tehnika i Tehnologiâ, Vol. 50(4), pp. 41 - 46.

Mahmoud, M.M., Karayiannis, T.G., 2013. "Heat transfer correlation for flow boiling in small to micro tubes”. International Journal of Heat and Mass Transfer, Vol. 66, pp. 553 - 574.

Oliveira, J.D., Zanette, G.P., Coan, P.W., Passos, J.C., Güths, S., Copetti, J.B., 2015. Uncertainty analysis during vapor flow inside MPE microchannels. In: 23rd ABCM International Congress of Mechanical Engineering - COBEM 2015. Rio de Janeiro, Brazil.

Oliveira, J.D., Copetti, J.B., Passos, J.C., 2016. “An experimental investigation on flow boiling heat transfer of R-600a in a horizontal small tube”. International Journal of Refrigeration, Vol. 72, pp. $97-110$.

Oliveira, J.D., Copetti, J.B., Passos, J.C., 2017. "Experimental investigation on flow boiling pressure drop of R-290 and R-600a in a horizontal small tube". International Journal of Refrigeration, In Press, Accepted Manuscript.

Ong, C. L., Thome, J. R., 2011. "Macro-to-microchannel transition in two-phase flow: Part 1 Two-phase flow patterns and film thickness measurements”. International Journal of Thermal Fluid Science, Vol. 35, pp. 37 - 47.

Pettersen, J., 2004. "Flow vaporization of $\mathrm{CO}_{2}$ in microchannel tubes". Experimental Thermal and Fluid Science, Vol. 28, pp. $111-121$.

Qiu, J., Zhang, H., Yu, X., Qi, Y., Lou, J., Wang, X., 2015. “Experimental investigation of flow boiling heat transfer and pressure drops characteristic of R1234ze(E), R600a, and a mixture of R1234ze(E)/R32 in a horizontal smooth tube”. Advances in Mechanical Engineering, Vol. 7(9), pp. $1-12$.

Revellin, R., Thome, J.R., 2007. "New type of diabatic flow pattern map for boiling heat transfer in microchannels”. Journal of Micromechanics and Microengineering, Vol. 17, pp. 788 - 796. 
Rouhani, S.Z., Axelsson, E., 1970. "Calculations of void volume fraction in the subcooled and quality boiling region”. International Journal of Heat and Mass Transfer, Vol. 13, pp. 383 393.

Sempértegui-Tapia, D.F., Ribatski, G., 2017. "Flow boiling heat transfer of R134a and low GWP refrigerants in a horizontal micro-scale channel”. International Journal of Heat and Mass Transfer, Vol. 108, pp. 2417 - 2432.

Shafaee, M., Mashouf, H., Sarmadian, A., Mohseni, S.G., 2016a. "Evaporation heat transfer and pressure drop characteristics of R-600a in horizontal smooth and helically dimpled tubes". Applied Thermal Engineering, Vol. 107, pp. 28 - 36.

Shafaee, M., Alimardani, F., Mohseni, S.G., 2016b. “An empirical study on evaporation heat transfer characteristics and flow pattern visualization in tubes with coiled wire inserts". International Communications in Heat and Mass Transfer, Vol. 76, pp. 301 - 307.

Sun, L., Mishima, K., 2009. “An evaluation of prediction methods for saturated flow boiling heat transfer in mini-channels”. International Journal of Heat and Mass Transfer, Vol. 52, pp. 5323 5329.

Taitel, Y., Dukler, A.E., 1976. "A model for predicting flow regime transitions in horizontal and near horizontal gas-liquid flow”. AIChE Journal, Vol. 22(2), pp. 43 - 55.

Tibiriçá, C.B., Ribatski, G., 2010. "Flow Boiling heat transfer of R134a and R245fa in a $2.3 \mathrm{~mm}$ tube”. International Journal of Heat and Mass Transfer, Vol. 53, 2459 - 2468.

Wang, S., Gong, M.Q., Chen, G.F., Sun, Z.H., Wu, J.F., 2014. "Two-phase heat transfer and pressure drop of propane during saturated flow boiling inside a horizontal tube”. International Journal of Refrigeration, Vol. 41, pp. 200 - 209.

Wen, M.-Y., Ho, C.-Y., Jang, J.-K., 2007. "Boiling heat transfer of refrigerant R-600a/R-290-oil mixtures in the serpentine small-diameter U-tubes". Applied Thermal Engineering, Vol. 27, pp. $2353-2362$.

Wen, M.-Y., Jang, K.-J., Ho, C.-Y., 2014. “The characteristics of boiling heat transfer and pressure drop of R-600a in a circular tube with porous inserts". Applied Thermal Engineering, Vol. 64, pp. $348-357$.

Wojtan, L., Ursenbacher, T., Thome, J.R., 2005. "Investigation of flow boiling in horizontal tubes: Part I - A new diabatic two-phase flow pattern map”. International Journal of Heat Mass Transfer, Vol. 48(14), pp. 2955 - 2969.

Yang, Z., Gong, M., Chen, G., Zou, X., Shen, J., 2017. “Two-phase flow patterns, heat transfer and pressure drop characteristics of R600a during flow boiling inside a horizontal tube”. Applied Thermal Engineering, Vol. 120, pp. 654 - 671. 


\section{List of Figures}

Figure 1. (a) Experimental test rig; (b) Schematic of test section and thermocouples in different positions along the tube.

Figure 2. Comparative between experimental and predicted heat transfer coefficients given by Dittus-Boelter (1930) and Gnielinski (1970).

Figure 3. Two phase flow patterns observed during the tests.

Figure 4. Comparison between Ong and Thome (2011) flow pattern map and flow patterns observed in the present investigation.

Figure 5. $\beta$ as a function of (a) vapor quality and (b) void fraction for propane.

Figure 6. Local heat transfer coefficients versus vapor quality at constant mass fluxes: (a) $240 \mathrm{~kg} /\left(\mathrm{m}^{2} \mathrm{~s}\right) ;$ (b) $320 \mathrm{~kg} /\left(\mathrm{m}^{2} \mathrm{~s}\right) ;$ (c) $400 \mathrm{~kg} /\left(\mathrm{m}^{2} \mathrm{~s}\right) ;$ (d) $480 \mathrm{~kg} /\left(\mathrm{m}^{2} \mathrm{~s}\right)$.

Figure 7. Effect of mass flux on local heat transfer coefficient: (a) For $G=240 \mathrm{~kg} /\left(\mathrm{m}^{2} \mathrm{~s}\right)$ and $480 \mathrm{~kg} /\left(\mathrm{m}^{2} \mathrm{~s}\right), q^{\prime \prime} T S=10 \mathrm{~kW} / \mathrm{m}^{2}$ and $60 \mathrm{~kW} / \mathrm{m}^{2}$; (b) For $G=240 \mathrm{~kg} /\left(\mathrm{m}^{2} \mathrm{~s}\right)$ and $320 \mathrm{~kg} /\left(\mathrm{m}^{2} \mathrm{~s}\right)$, $q " T S=20 \mathrm{~kW} / \mathrm{m}^{2}$ and $60 \mathrm{~kW} / \mathrm{m}^{2}$.

Figure 8. Boiling curves for $x_{(i-T S)}=0.20$ and different mass fluxes, $G$.

Figure 9. Difference between both heat transfer coefficient of the top and bottom points at the position $z_{5}$ in the test section.

Figure 10. Experimental versus predicted heat transfer coefficient applying different correlations: (a) Kew and Cornwell (1997), (b) Kandlikar Balasubramanian (2004), (c) Sun and Mishima (2009), (d) Bertsch et al. (2009), (e) Li and Wu (2010), (f) Kim and Mudawar (2013), (g) Mahmoud and Karayiannis (2013) and (h) Sempértegui-Tapia and Ribatski (2017).

Figure 11. Comparison between some experimental and predicted results as function of vapor quality. 


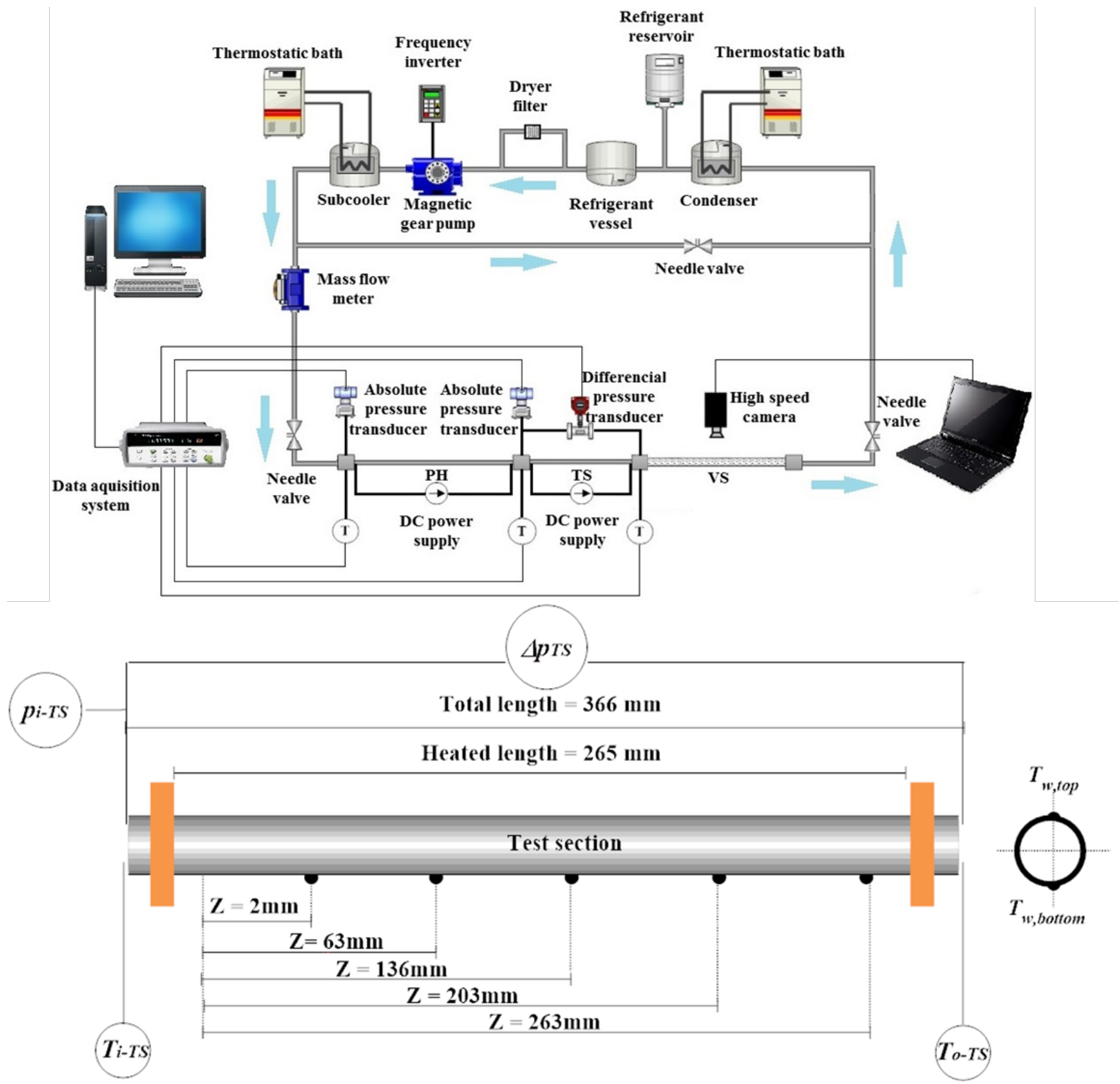

Figure 1. (a) Experimental test rig; (b) Schematic of test section and thermocouples in different positions along the tube. 


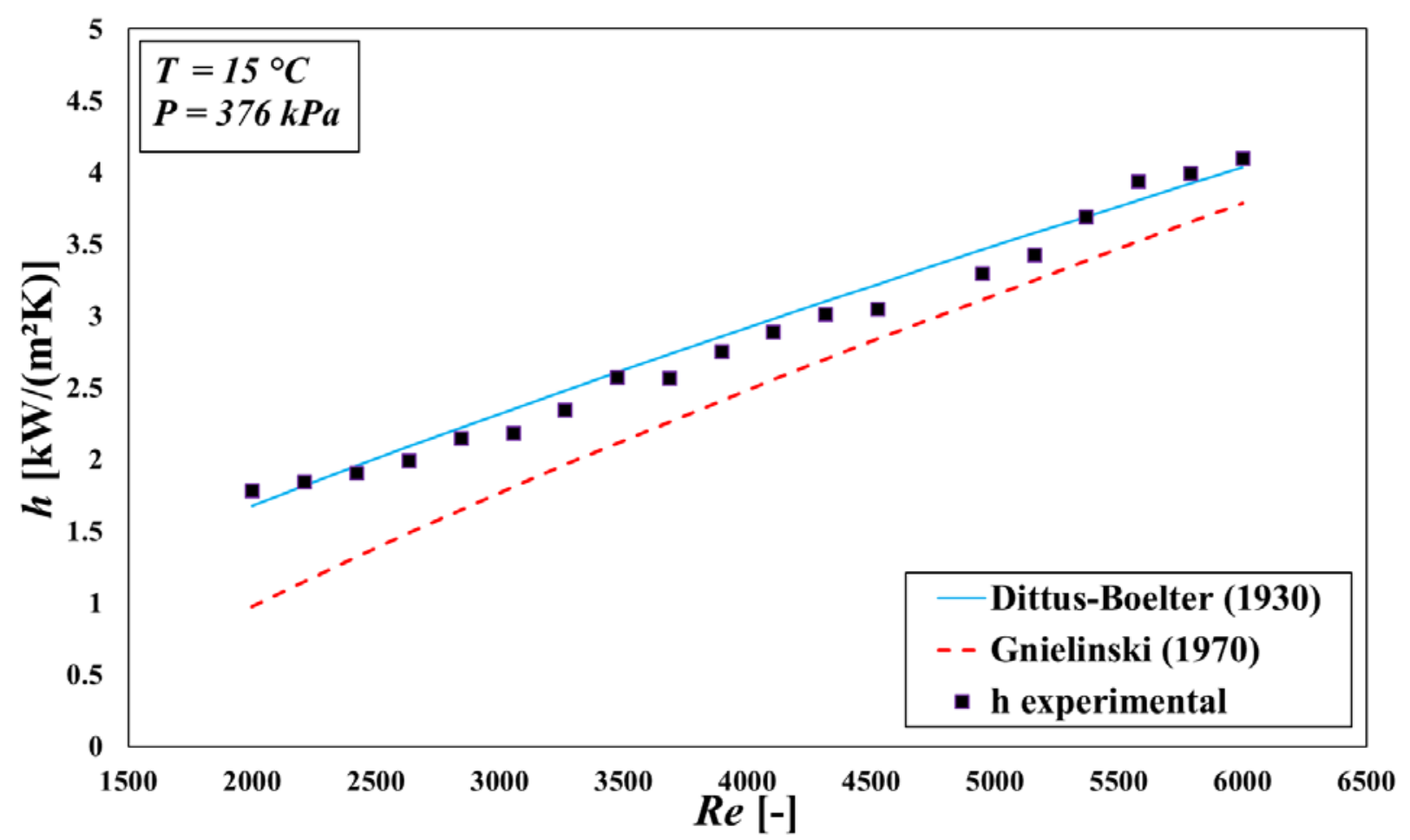

Figure 2. Comparative between experimental and predicted heat transfer coefficients given by Dittus-Boelter (1930) and Gnielinski (1970). 


\begin{tabular}{|c|c|c|c|c|c|}
\hline \multicolumn{6}{|c|}{ Bubbly/plug } \\
\hline$q^{\prime \prime}\left[\mathrm{kW} / \mathrm{m}^{2}\right]$ & $G\left[\mathrm{~kg} /\left(\mathrm{m}^{2} \mathrm{~s}\right)\right]$ & $X_{o-T S}[-]$ & $\alpha_{o-T S}[-]$ & $S[-]$ & \multirow{3}{*}{$\begin{array}{c}\text { Bo }^{\prime} 10^{5}[-] \\
2.993\end{array}$} \\
\hline & 480 & 0.03 & 0.39 & 1.34 & \\
\hline Flow directior & 样 & 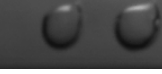 & 0 & & \\
\hline \multicolumn{6}{|c|}{ Plug } \\
\hline$q^{\prime \prime}\left[\mathrm{kW} / \mathrm{m}^{2}\right]$ & $G\left[\mathrm{~kg} /\left(\mathrm{m}^{2} \mathrm{~s}\right)\right]$ & $x_{o-T S}[-]$ & $\alpha_{o-T S}[-]$ & $S[-]$ & \multirow{2}{*}{$\begin{array}{c}\text { Bo } \cdot 10^{5}[-] \\
\quad 6.005\end{array}$} \\
\hline & 240 & 0.05 & 0.511 & 1.38 & \\
\hline \multicolumn{6}{|c|}{ Slug } \\
\hline$q^{\prime \prime}\left[\mathrm{kW} / \mathrm{m}^{2}\right]$ & $G\left[\mathrm{~kg} /\left(\mathrm{m}^{2} \mathrm{~s}\right)\right]$ & $x_{o-T S}[-]$ & $\alpha_{o-T S}[-]$ & $S[-]$ & \multirow{2}{*}{$\begin{array}{c}\text { Bo } \cdot 10^{5}[-] \\
\quad 7.203\end{array}$} \\
\hline 10 & 400 & 0.11 & 0.65 & 1.5 & \\
\hline \multicolumn{6}{|c|}{ Churn } \\
\hline$q^{\prime \prime}\left[\mathbf{k W} / \mathbf{m}^{2}\right]$ & $G\left[\mathrm{~kg} /\left(\mathrm{m}^{2} \mathrm{~s}\right)\right]$ & $X_{0-T S}[-]$ & $\alpha_{o-T S}[-]$ & $S[-]$ & \multirow{2}{*}{$\begin{array}{c}B o \cdot 10^{4}[-] \\
\quad 3.694\end{array}$} \\
\hline 40 & 320 & 0.37 & 0.86 & 2.35 & \\
\hline \multicolumn{6}{|c|}{ Wavy annular } \\
\hline$q^{\prime \prime}\left[\mathrm{kW} / \mathrm{m}^{2}\right]$ & $G\left[\mathrm{~kg} /\left(\mathrm{m}^{2} \mathrm{~s}\right)\right]$ & $X_{o-T S}[-]$ & $\alpha_{o-T S}[-]$ & $S[-]$ & \multirow{2}{*}{$\begin{array}{c}B o \cdot 10^{4}[-] \\
4.55\end{array}$} \\
\hline 60 & 400 & 0.44 & 0.88 & 2.5 & \\
\hline \multicolumn{6}{|c|}{ Smooth annular } \\
\hline$q^{\prime \prime}\left[\mathrm{kW} / \mathrm{m}^{2}\right]$ & $G\left[\mathrm{~kg} /\left(\mathrm{m}^{2} \mathrm{~s}\right)\right]$ & $X_{o-T S}[-]$ & $\alpha_{o-T S}[-]$ & $S[-]$ & $B o \cdot 10^{4}[-]$ \\
\hline 60 & 240 & 0.99 & 0.99 & 4.47 & 7.46 \\
\hline
\end{tabular}

Figure 3. Two phase flow patterns observed during the tests. 



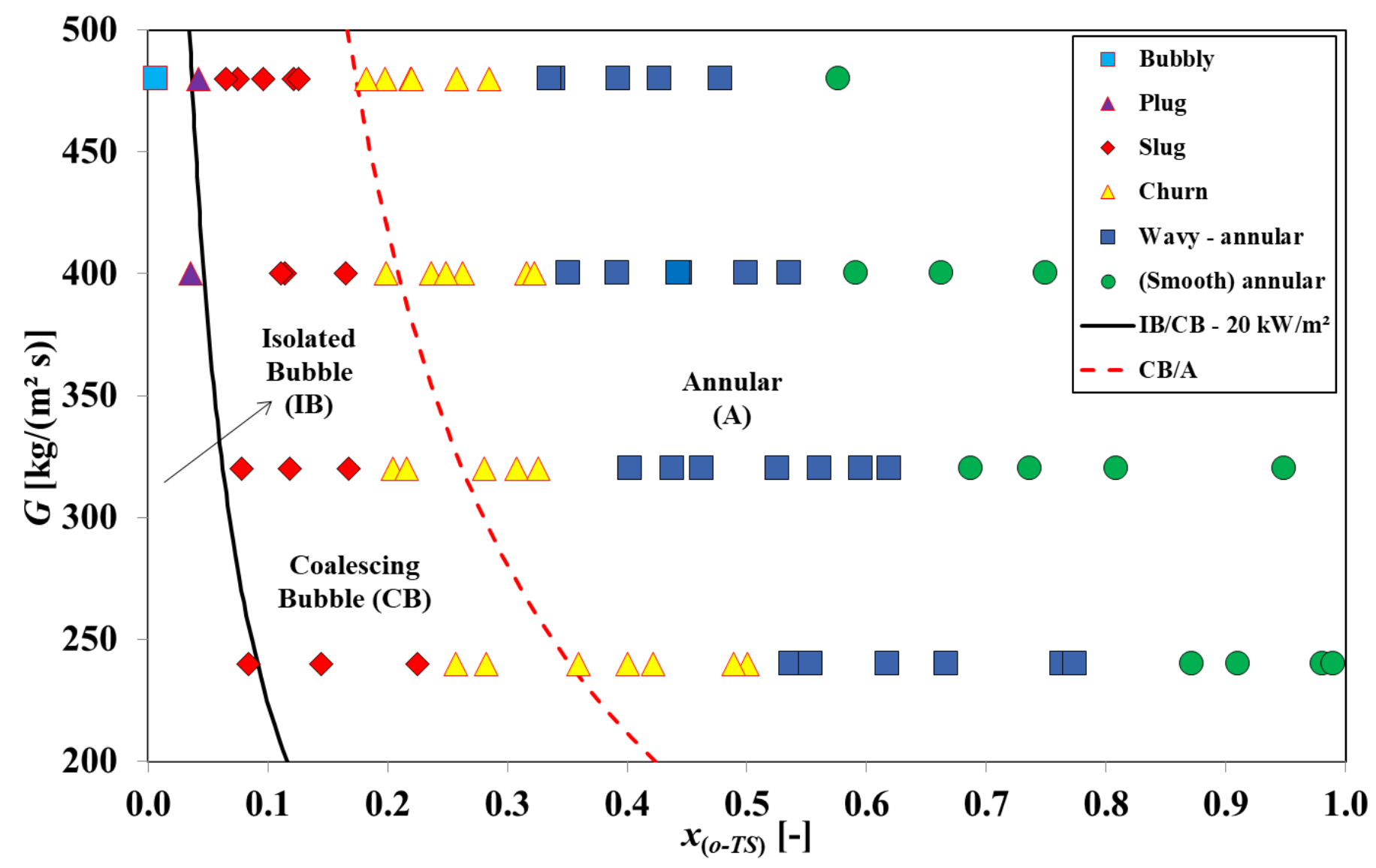

Figure 4. Comparison between Ong and Thome (2011) flow pattern map and flow patterns observed in the present investigation. 

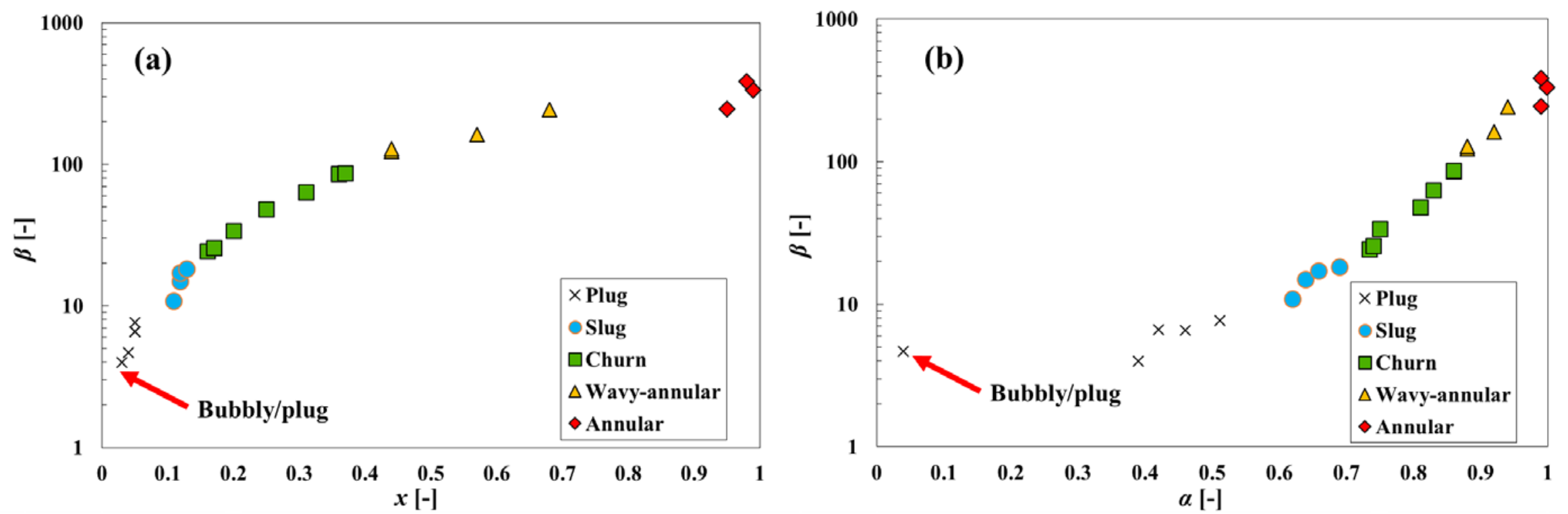

Figure 5. $\beta$ as a function of (a) vapor quality and (b) void fraction for propane. 

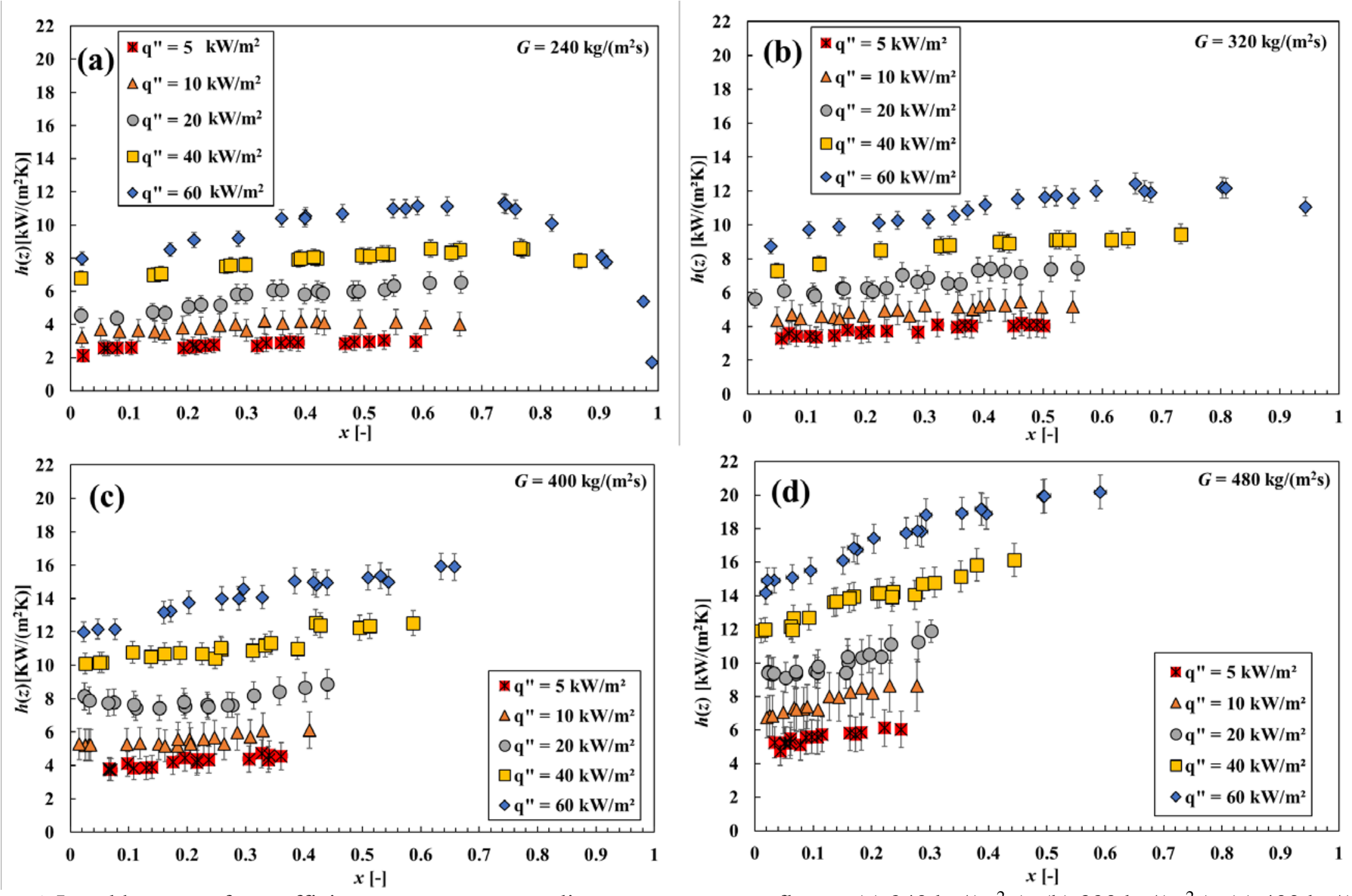

Figure 6. Local heat transfer coefficients versus vapor quality at constant mass fluxes: (a) $240 \mathrm{~kg} /\left(\mathrm{m}^{2} \mathrm{~s}\right) ;$ (b) $320 \mathrm{~kg} /\left(\mathrm{m}^{2} \mathrm{~s}\right)$; (c) $400 \mathrm{~kg} /\left(\mathrm{m}^{2} \mathrm{~s}\right)$; (d) $480 \mathrm{~kg} /\left(\mathrm{m}^{2} \mathrm{~s}\right)$. 

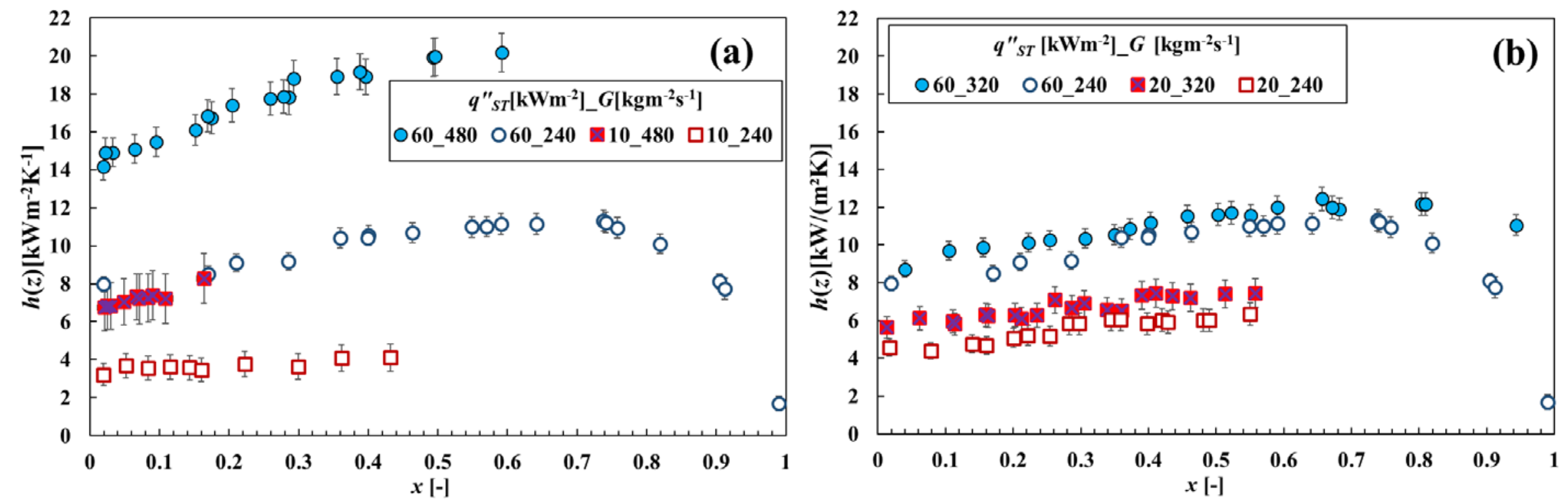

Figure 7. Effect of mass flux on local heat transfer coefficient: (a) For $G=240 \mathrm{~kg} /\left(\mathrm{m}^{2} \mathrm{~s}\right)$ and $480 \mathrm{~kg} /\left(\mathrm{m}^{2} \mathrm{~s}\right), q^{\prime}$ TS $=10 \mathrm{~kW} / \mathrm{m}^{2}$ and $60 \mathrm{~kW} / \mathrm{m}^{2}$; (b) For $G=240 \mathrm{~kg} /\left(\mathrm{m}^{2} \mathrm{~s}\right)$ and $320 \mathrm{~kg} /\left(\mathrm{m}^{2} \mathrm{~s}\right), q^{\prime \prime} T \mathrm{~s}=20 \mathrm{~kW} / \mathrm{m}^{2}$ and $60 \mathrm{~kW} / \mathrm{m}^{2}$. 


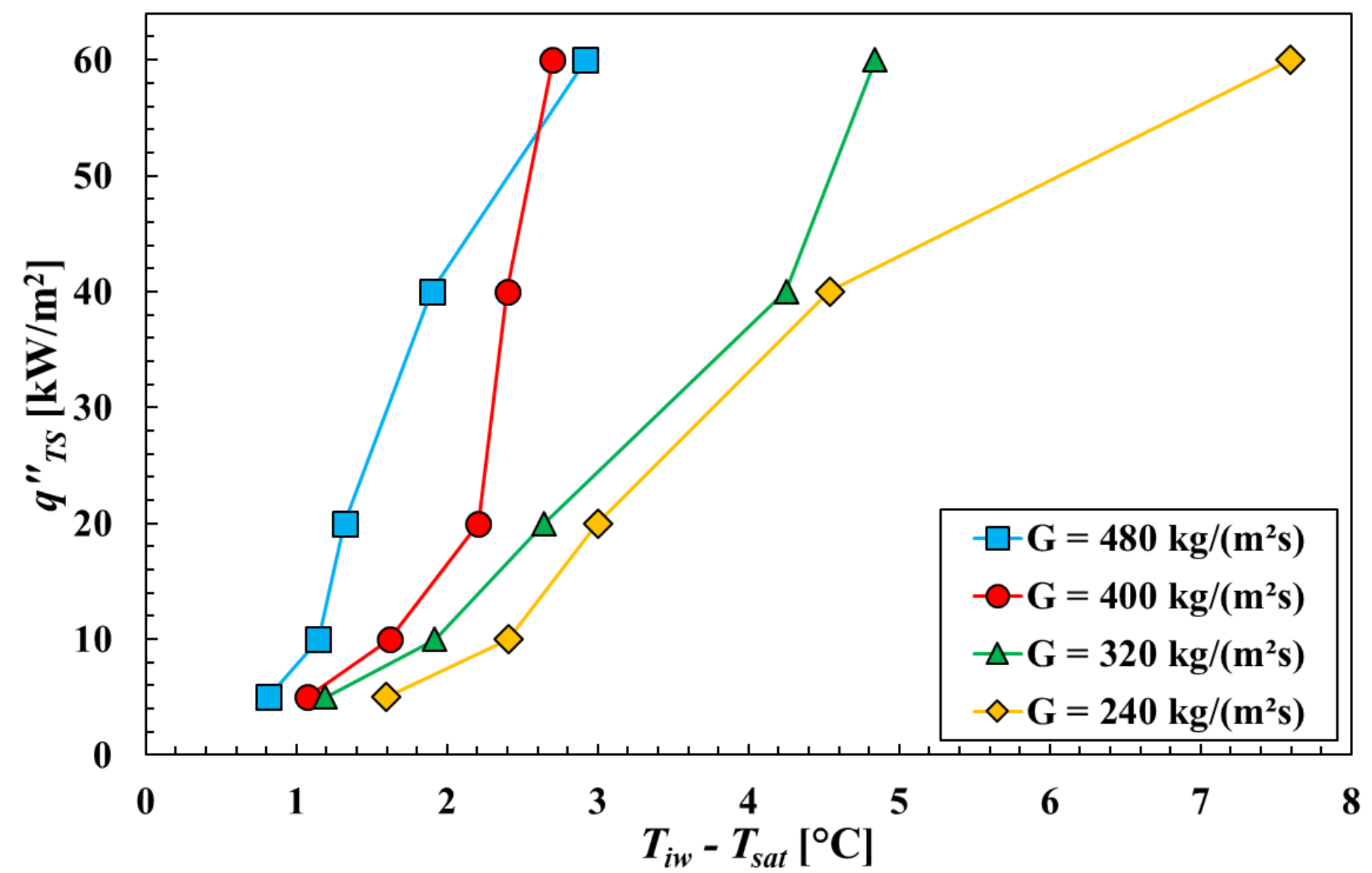

Figure 8. Boiling curves for $x_{(i-T S)}=0.20$ and different mass fluxes, $G$. 


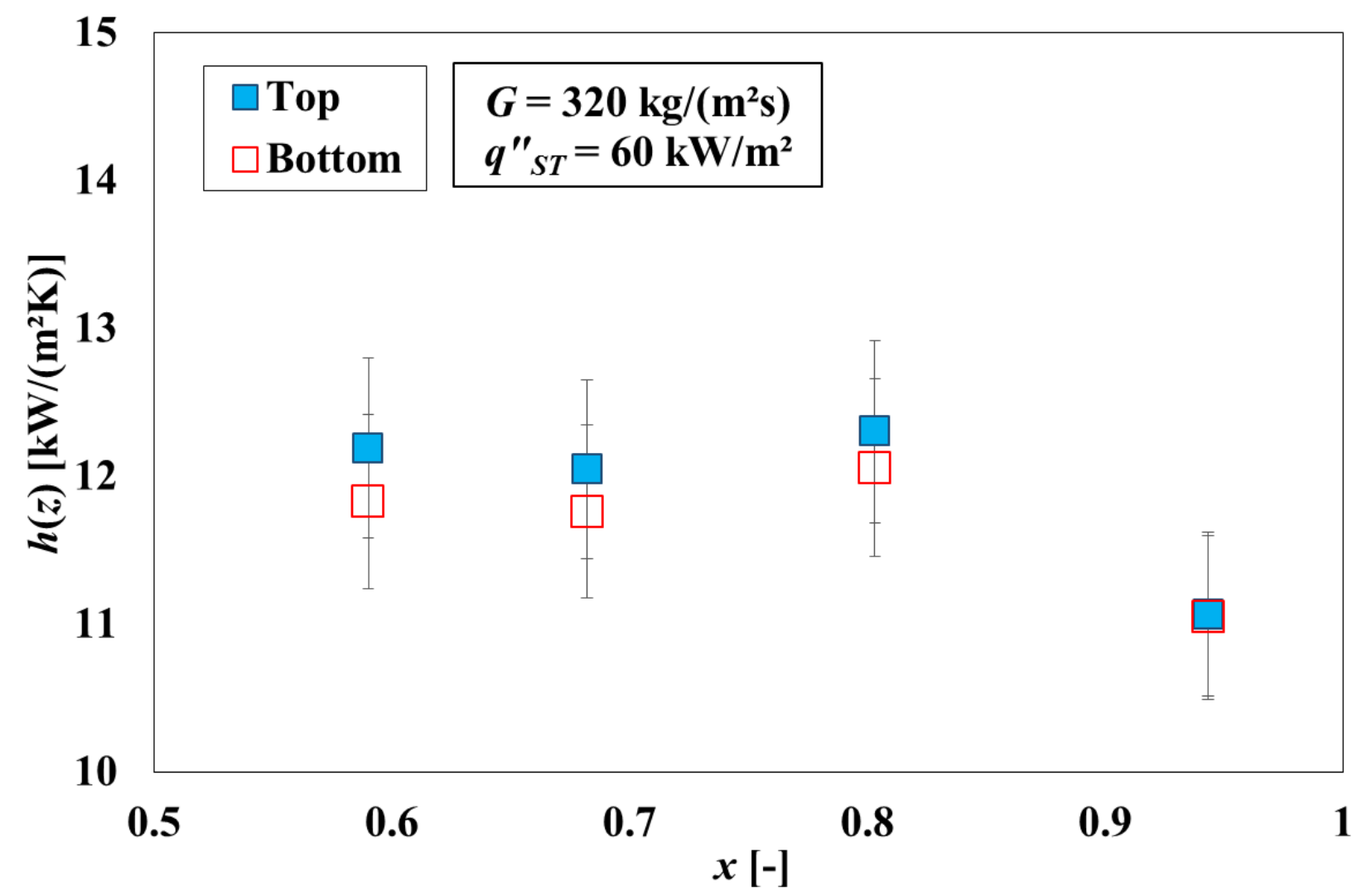

Figure 9. Difference between both heat transfer coefficient of the top and bottom points at the position $z_{5}$ in the test section. 

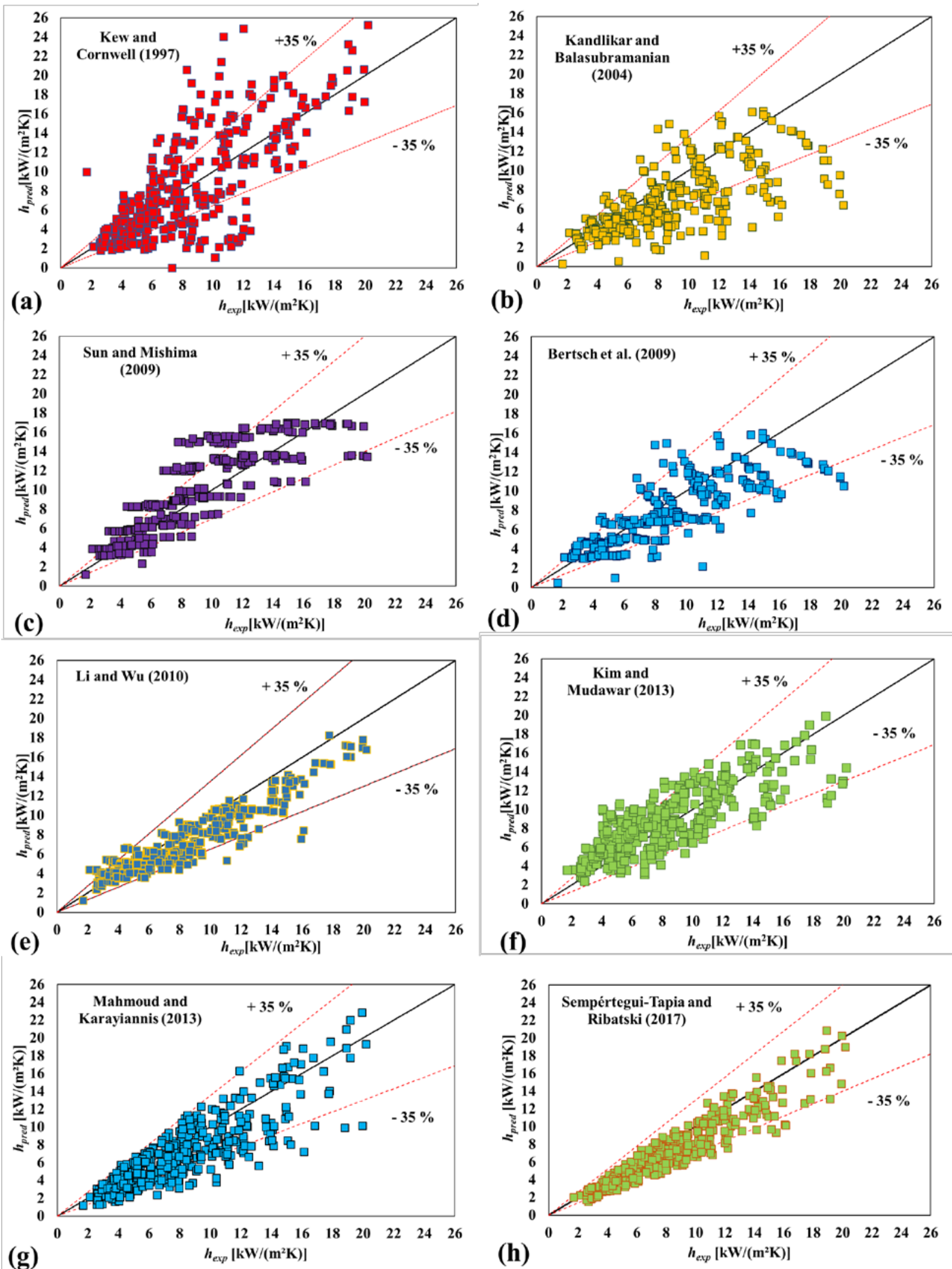

Figure 10. Experimental versus predicted heat transfer coefficient applying different correlations:

(a) Kew and Cornwell (1997), (b) Kandlikar Balasubramanian (2004), (c) Sun and Mishima (2009), (d) Bertsch et al. (2009), (e) Li and Wu (2010), (f) Kim and Mudawar (2013), (g)

Mahmoud and Karayiannis (2013) and (h) Sempértegui-Tapia and Ribatski (2017). 


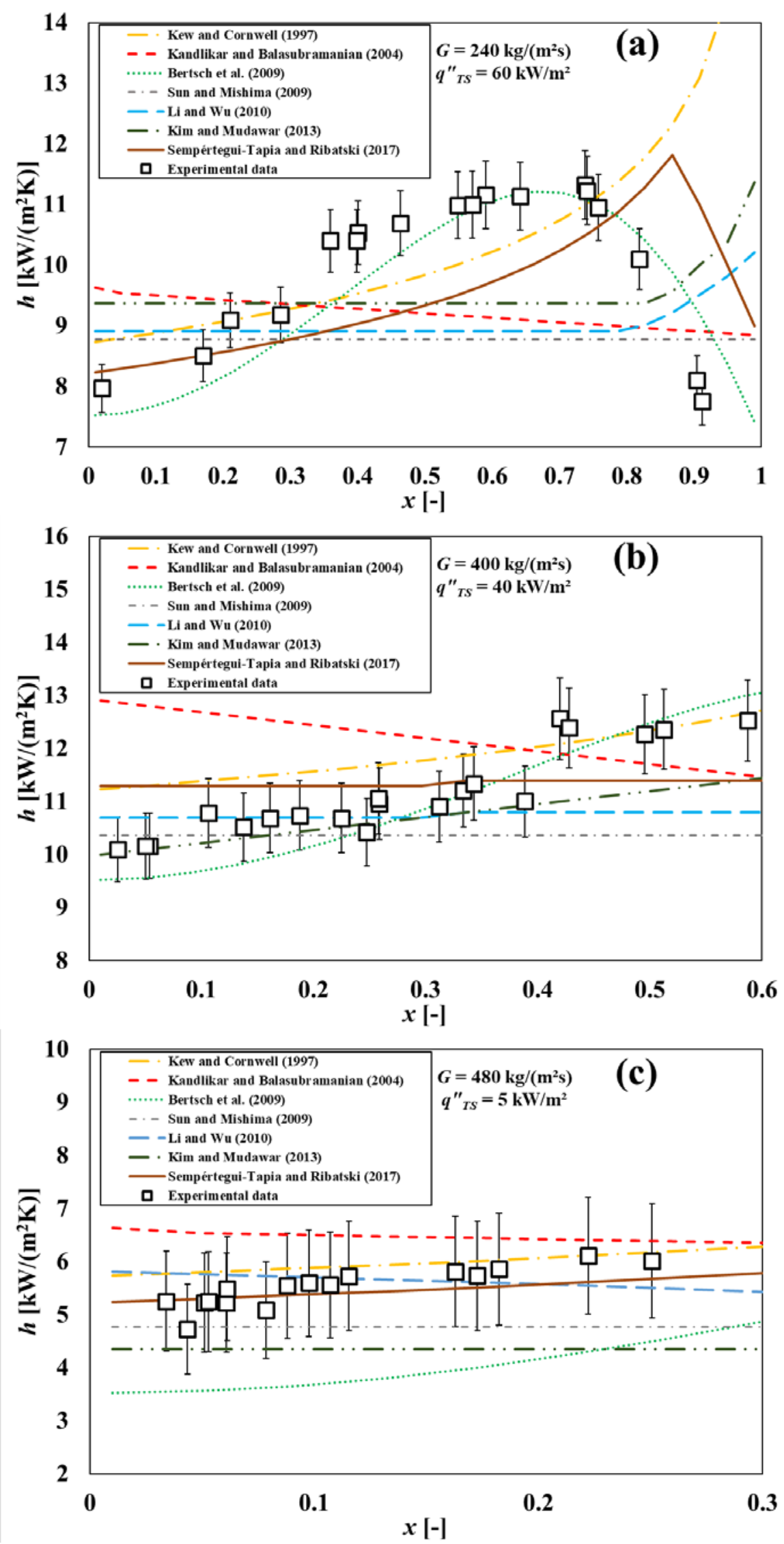

Figure 11. Comparison between some experimental and predicted results as function of vapor quality for different conditions of both mass and heat transfer. 


\section{List of Tables}

Table 1 - Summary of more recent flow boiling experiments using pure hydrocarbons and mixtures.

Table 2 - Experimental conditions of present study.

Table 3 - Characteristics of instruments, parameters and uncertainty.

Table 4 - Proposed variation of the parameter ß to characterize flow pattern for R-290.

Table 5 - Statistical results of comparison of heat transfer coefficient. 
Table 1 - Summary of more recent flow boiling experiments using pure hydrocarbons and mixtures.

\begin{tabular}{|c|c|c|c|c|c|c|c|c|}
\hline Author & Geometry & $\begin{array}{l}\text { Orientation/ } \\
\text { D [mm] }\end{array}$ & Fluids & $\mathbf{T}_{\text {sat }}\left[{ }^{\circ} \mathbf{C}\right]$ & $G\left[\mathrm{kgm}^{-2} \mathbf{s}^{-1}\right]$ & $q^{\prime \prime}\left[\mathrm{kWm}^{-2}\right]$ & $x[-]$ & Remarks \\
\hline Aprin et al. (2011) & NS & V/NS & R-600a, R-290 and R-601 & $*$ & $8-45$ & $3-53$ & NS & $\begin{array}{c}\text { * Saturation temperature was } \\
\text { obtained as a function of average } \\
\text { pressure ( } 0.2-12 \text { bar) } \\
\text { The heat transfer coefficient was } \\
\text { measured in a tube bundle. }\end{array}$ \\
\hline $\begin{array}{l}\text { Maqbool et al. } \\
\text { (2013) }\end{array}$ & C & $\mathrm{V} / \mathbf{1 . 7}$ & R-290 & 23, 33 and 43 & $100-500$ & $5-280$ & $0.0-1$ & - \\
\hline Chen and Shi (2013) & C & H/8.0 & LNG & $*$ & $49.2-201.8$ & $8-36$ & NS & $\begin{array}{c}\text { *Saturation condition was } \\
\text { established as a function of inlet } \\
\text { pressure ranging from } 65.7 \text { to } \\
82.2 \mathrm{kPa} \\
\end{array}$ \\
\hline Wen et al. (2014) & C & H/7.5 & R-600a & 10 & $120-1100$ & $12-65$ & $0.076-0.87$ & $\begin{array}{l}\text { Both heat transfer and pressure } \\
\text { drop were studied in a } \\
\text { circular pipe within dispersed- } \\
\text { copper porous inserts }\end{array}$ \\
\hline Anwar et al. (2015) & $\mathrm{C}$ & $\begin{array}{ll}\text { V/1.6 } \\
\end{array}$ & R-600a & 27 and 32 & $50-350$ & $20-130$ & $0.0-0.97$ & Dry-out effect was observed \\
\hline Chen at al. (2015) & $\mathbf{C}$ & $\mathrm{H} / 5.4$ & R-600a+mineral naphthalin oil & NS & $11.9-15.99$ & $2.5-3.3$ & Up to 0.95 & - \\
\hline $\begin{array}{c}\text { Melnyk and } \\
\text { Zhelezny (2015) } \\
\end{array}$ & C & $H / 5.4$ & R-600a+mineral naphthalin oil & NS & $14.75-18.36$ & $\approx 3.8$ & Up to 0.97 & - \\
\hline Qiu et al. (2015) & C & $\mathrm{H} / \mathbf{8}$ & $\begin{array}{c}\text { R-600a, R-1234ze(E) and } \\
\text { R1234ze(E)/R32 (27/73 mass \%) }\end{array}$ & 20 & $200-400$ & $5-10$ & $0.05-0.85$ & $\begin{array}{c}\begin{array}{c}\text { Both heat transfer and pressure } \\
\text { drop were studied }\end{array} \\
\end{array}$ \\
\hline $\begin{array}{c}\text { Apaydin and } \\
\text { Heperkan (2016) } \\
\end{array}$ & C & $\mathrm{V} / 0.8$ & R-600a & - & $8.99-9.97$ & $\begin{array}{l}\text { Adiabatic } \\
\text { condition }\end{array}$ & NS & - \\
\hline $\begin{array}{c}\text { Kanizawa et al. } \\
(2016)\end{array}$ & C & $\mathrm{H} / \mathbf{0 . 3 8}-2.6$ & R-134a, R-245fa and R-600a & $21.5-58.3$ & $49-2200$ & $5-185$ & $0.01-0.93$ & - \\
\hline $\begin{array}{l}\text { Shafaee et al. } \\
\quad(2016 b)\end{array}$ & C & $\begin{array}{c}\mathrm{H} / * 0.5,1.0 \text { and } \\
1.5\end{array}$ & R-600a & $* *$ & $109.2-505$ & $6-40$ & $0.08-0.7$ & $\begin{array}{c}* \text { Coiled wire insert tubes. } \\
* * \text { Saturation temperature was } \\
\text { obtained as a function of average } \\
\text { pressure }(4-6 \text { bar })\end{array}$ \\
\hline Chávez et al (2017) & $\mathbf{R}$ & $\mathbf{H} / *$ & R-600a, R-290 and R-1270 & 25 & $165-823$ & Up to 400 & NS & $\begin{array}{l}\text { *The test section is composed of } \\
\text { fifty channels of cross sectional } \\
\text { areas of } 0.123 \times 0.494 \mathrm{~mm}^{2} \text {. } \\
\text { ONB was analyzed as function of } \\
\text { mass flux, subcooling conditions } \\
\text { and heat flux. } \\
\end{array}$ \\
\hline Del Col et al. (2017) & C & H/0.96 & R-1270 & 30 & $100-600$ & $11-244$ & $0.02-0.62$ & $\begin{array}{c}\text { Condensation heat transfer of } \\
\text { R-290 and R-1270 was also } \\
\text { studied. } \\
\end{array}$ \\
\hline Oliveira et al. (2017) & $\mathrm{C}$ & H/1.0 & R-600a and R-290 & 25 & $240-480$ & $5-60$ & $0.0-0.99$ & - \\
\hline $\begin{array}{l}\text { Sempértegui-Tapia } \\
\text { et al. (2017) }\end{array}$ & C & H/1.1 & $\begin{array}{l}\text { R-134a, R-1234yf, R-1234ze(E) } \\
\text { and R-600a }\end{array}$ & 31 and 41 & $200-800$ & $15-145$ & $0.05-0.95$ & - \\
\hline Yang et al. (2017) & $\mathbf{C}$ & $\mathrm{H} / 6$ & R-600a & 9.2, 21.3 and 30.8 & $67-194$ & $10.6-75$ & $0-1.0$ & - \\
\hline
\end{tabular}




\begin{tabular}{rll}
\hline Table 2 - Experimental conditions of present study. & \\
\hline Parameter & Values & Unit \\
\hline Heat flux in test section, $q$ "TS & $5,10,20,40,60$ & $\mathrm{~kW} / \mathrm{m}^{2}$ \\
Heating power in pre-heater, $q_{P H}$ & $5,15,25,35$ & $\mathrm{~W}$ \\
Mass flux, $G$ & $240,320,400,480$ & $\mathrm{~kg} /\left(\mathrm{m}^{2} \mathrm{~s}\right)$ \\
Saturation temperature, $T_{\text {sat }}$ & 25 & ${ }^{\circ} \mathrm{C}$ \\
Saturation pressure, $p_{\text {sat }}$ & 952.2 & $\mathrm{kPa}$ \\
\hline
\end{tabular}

\begin{tabular}{|c|c|c|c|}
\hline Parameter & Instrument & Range & Uncertainty \\
\hline Temperature & $\begin{array}{c}\text { Type - E } \\
\text { Thermocouple }\end{array}$ & $-200^{\circ} \mathrm{C}$ to $+900^{\circ} \mathrm{C}$ & $u(T)\left[ \pm 0.25^{\circ} \mathrm{C}\right]$ \\
\hline Heat flux & $\begin{array}{l}\text { DC power } \\
\text { supply }\end{array}$ & 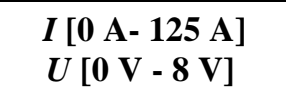 & $\begin{array}{c}u(I)[500 \mathrm{~mA}] \\
u(U)[8 \mathrm{mV}]\end{array}$ \\
\hline $\begin{array}{c}\text { Saturation } \\
\text { Temperature }\end{array}$ & - & - & $u\left(T_{s a t}(z)\right)\left[ \pm 0.1^{\circ} \mathrm{C}\right]$ \\
\hline $\begin{array}{c}\text { Heat transfer } \\
\text { coefficient }\end{array}$ & - & $\begin{array}{c}2.13 \mathrm{~kW} /\left(\mathrm{m}^{2} \mathrm{~K}\right) \\
- \\
20.18 \mathrm{~kW} /\left(\mathrm{m}^{2} \mathrm{~K}\right)\end{array}$ & For $\begin{aligned} q " T S & =5 \mathrm{~kW} / \mathrm{m}^{2}, \mathbf{u}(\mathbf{h}(\mathrm{z})) / \mathrm{h}(\mathrm{z})[17.9 \%-34.3 \%] \\
q " T S & =10 \mathrm{~kW} / \mathrm{m}^{2}, \mathbf{u}(\mathbf{h}(\mathrm{z})) / \mathrm{h}(\mathrm{z})[12.1 \%-33.2 \%] \\
q " T S & =20 \mathrm{~kW} / \mathrm{m}^{2}, \mathbf{u}(\mathbf{h}(\mathrm{z})) / \mathrm{h}(\mathrm{z})[8.2 \%-19.2 \%] \\
q " T S & =40 \mathrm{~kW} / \mathrm{m}^{2}, \mathbf{u}(\mathbf{h}(\mathrm{z})) / \mathrm{h}(\mathrm{z})[5.8 \%-13.1 \%] \\
q " T S & =60 \mathrm{~kW} / \mathrm{m}^{2}, \mathbf{u}(\mathrm{h}(\mathrm{z})) / \mathrm{h}(\mathrm{z})[4.9 \%-9.8 \%]\end{aligned}$ \\
\hline Vapor quality & - & $0-0.99$ & 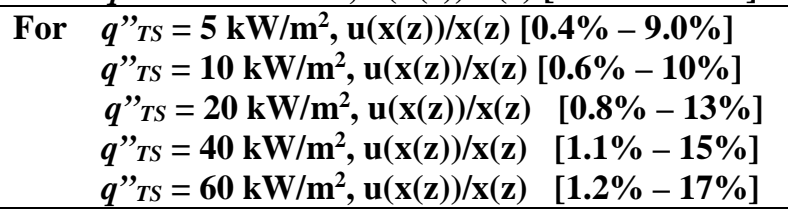 \\
\hline
\end{tabular}




\begin{tabular}{cc}
\hline Table 4 - Proposed variation of the parameter $\boldsymbol{\beta}$ to \\
characterize flow pattern for $\mathbf{R}-290$. \\
\hline Bubbly/plug & $\boldsymbol{\beta} \leq 4$ \\
Plug & $4<\boldsymbol{\beta}<10$ \\
Slug & $10<\boldsymbol{\beta}<20$ \\
Churn & $20<\boldsymbol{\beta}<125$ \\
Wavy-annular & $125<\boldsymbol{\beta}<245$ \\
Smooth-annular & $\boldsymbol{\beta} \geq 245$ \\
\hline
\end{tabular}

\begin{tabular}{cccc}
\hline \multicolumn{4}{c}{ Table 5 - Statistical results of comparison of heat transfer coefficient. } \\
\hline Author & MBE (\%) & RMSE (\%) & DPEB (\%) \\
\hline Kew and Cornwell (1997) & 16.4 & 48.58 & 59 \\
Kandlikar and Balasubramanian (2004) & -16.1 & 31.2 & 61.8 \\
Sun and Mishima (2009) & 15.2 & 30.5 & 88.5 \\
Bertsch et al. (2009) & -6.64 & 25.25 & 90.3 \\
Li and Wu (2010) & -8.5 & 20.8 & 97.8 \\
Kim and Mudawar (2013) & 16.01 & 37.82 & 78 \\
Mahmoud and Karayiannis (2013) & -14.8 & 39.04 & 69.1 \\
Sempértegui-Tapia and Ribatski (2017) & -9.8 & 23.4 & 94.2 \\
\hline
\end{tabular}

